Chapter 3

\title{
The Evolving Role of Opioid Treatment in Chronic Pain Management
}

\author{
Hans Hansen, Carl E. Noe and Gabor B. Racz \\ Additional information is available at the end of the chapter \\ http://dx.doi.org/10.5772/58818
}

\section{Introduction}

Opioids for chronic pain management have become increasingly controversial, yet many patients continue to be treated with high doses for prolonged periods of time. The misconception between patients and providers alike is that these drugs can be taken without consequences. This liberalized thinking is far from the clinical practice of just two decades ago. Opioids have been destigmatized, and the origins can be traced to industry and a few thought leaders that have since retracted their belief that opioids may be prescribed without negative consequences.

During the 1990's chronic and cancer pain was recognized as being undertreated worldwide. The result was to soften prescribing resistance, particularly in the United States. As a result, many states in the U.S. passed intractable pain treatment acts to protect physicians from disciplinary action when prescribing opioids for non-cancer pain, as well as cancer pain. Unfortunately, that liberalization of opioid prescribing has been associated with a parallel increase in prescription opioid overdoses and deaths. Over the past decade, opioid overdose risk has become such a serious risk factor that Naloxone rescue units have been developed for home use. This rampant failing of safe prescribing habitry has resulted in a ready supply of opioids and a willingness of the consumer to seek these drugs.

Healthy Americans issued a report in October 2013 stating:

"Drug overdose deaths exceed motor vehicle-related deaths in 29 states and Washington DC. Misuse and abuse of prescription drugs costs the country an estimated \$ 53.4 billion a year in lost productivity, medical costs and criminal justice costs, and currently only one in 10 Americans with a substance abuse disorder receive treatment." [1] Clearly, the indiscriminate 
use of opioids has overwhelmed practical and safe prescribing methods, and regulatory agencies have been slow to respond to this opioid prescription epidemic.

This chapter will review recent studies on the subject of opioid prescribing, misuse, and abuse, and present arguments both for and against opioid therapy for chronic pain. Prescribing providers are encouraged to evaluate patients for risk factors of opioid abuse prior to initiating opioid therapy and during treatment. This is good medical practice. Additionally, it is stressed to prescribers to limit opioid doses and duration of drug exposure to further decrease the potential for adverse outcome. [2] Therefore, it is important to educate providers and patients about alternatives to opioids, including non-pharmacologic treatment, and introduce this multimodality concept.

Pain is subjective, and must be addressed from the patients' point of view. Most physicians struggle with pain as a diagnosis because there are few tools available to verify its existence. The value of advanced therapies, such as diagnostic interventions, help characterize the diagnosis, and opioids are rarely a first treatment step in the clinical treatment of chronic pain. Medical specialists are encouraged to improve sharing information about analgesic modalities and alternative interventions that may help an individual patient limit their opioid dose. Advanced therapies, such as interventional options, may not be known to midlevel providers who care for many patients with chronic conditions. Exhausting conservative measures to reduce the opioid load is necessary to optimize best clinical outcome and reduce risk in a clinical pain practice.

Opioid prescribing became an easy and time efficient method to treat pain in non-palliative care settings over the past two decades. The Federation of State Medical Boards endorsed opioids as a legitimate treatment option. [3] Like any clinical therapy, some patients seem to do very well with chronic opioid therapy while others do not. The overdose and diversion problems associated with increased opioid prescribing have recently called for enhanced regulatory activity from a public health perspective. Rethinking prescribing habits is different than relating new therapies in the traditional care model. Opioids are expected by patients, and as a society, expectations of relief are considered a "right", resistance to change is met with varying degrees of resistance. These layers of complexity in the clinical setting place the burden on the provider to secure a course of care that is compassionate, yet safe and effective.

Over the past 20 years, the prevalence of chronic pain and selecting the proper treatment has remained a consistent challenge for providers and patients alike. Advances in the treatment of chronic pain have primarily centered on pharmacologic management, therapy, and interventional tools. Positive outcomes are often associated with a multimodality approach, but the financial challenges of the healthcare system may limit access to these sophisticated treatment options. Long considered a fifth pathway, proper treatment of pain is necessary, but will be unlikely to support a priority position in the healthcare hierarchy of the future. With the emergence of innovative healthcare payment programs and strong government influence, priority will be given to chronic life-threatening disease states, and followed by those with progressive disabling afflictions. Chronic pain, which is often 
a cruel and disabling state, is not a life-threatening entity. In this rapidly evolving healthcare delivery system, the pain care provider will be challenged to render effective care, increase the quality of life of those in pain, and minimize risk and cost. Not surprisingly, it is expected that with rising healthcare costs, opioid use will be considered cheap, and a first choice. Escalating opioid use, however, has a direct relationship with adverse consequences. The rapidly increasing supply of opioids in the United States underscores this observation.

\begin{tabular}{|c|c|c|c|c|c|c|c|c|c|c|c|c|c|c|}
\hline DRUGS & ڤొ & ริ & ఫ્రి & 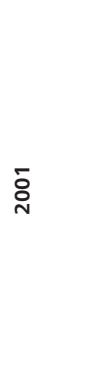 & ชิ & ֻ̊ํํ & ષ્ઠ & ڤั̊ & ๕ั & 옹 & : & ᄋ్̀ & 웅 & 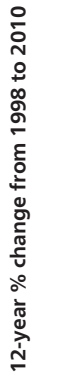 \\
\hline $\begin{array}{l}\text { Nonmedical } \\
\text { Use } \\
\text { of } \\
\text { Psychotherape } \\
\text { uitics } 2,3\end{array}$ & $\begin{array}{c}5.759 \\
(2.6 \%)\end{array}$ & $\begin{array}{c}9,220 \\
(4.2 \%)\end{array}$ & $\begin{array}{c}8,761 \\
(3.9 \%)\end{array}$ & $\begin{array}{l}11,102 \\
(4.9 \%)\end{array}$ & $\begin{array}{l}14,795 \\
(6.3 \%)\end{array}$ & $\begin{array}{l}15,163 \\
(6.4 \%)\end{array}$ & $\begin{array}{l}14,849 \\
(6.2 \%)\end{array}$ & $\begin{array}{l}15,346 \\
(6.3 \%)\end{array}$ & $\begin{array}{l}16,482 \\
(6.7 \%)\end{array}$ & $\begin{array}{l}16,280 \\
(6.6 \%)\end{array}$ & $\begin{array}{l}15,166 \\
(6.1 \%)\end{array}$ & $\begin{array}{l}16,006 \\
(6.4 \%)\end{array}$ & $\begin{array}{l}16,031 \\
(6.3 \%)\end{array}$ & $178 \%$ \\
\hline Pain Relievers & -- & $\begin{array}{c}6,582 \\
(3.0 \%)\end{array}$ & $\begin{array}{c}6,466 \\
(2.9 \%)\end{array}$ & $\begin{array}{c}8,353 \\
(3.7 \%)\end{array}$ & $\begin{array}{l}10,992 \\
(4.7 \%)\end{array}$ & $\begin{array}{l}11,671 \\
(4.9 \%)\end{array}$ & $\begin{array}{l}11,256 \\
(4.7 \%)\end{array}$ & $\begin{array}{l}11,815 \\
(4.9 \%)\end{array}$ & $\begin{array}{l}12,649 \\
(5.1 \%)\end{array}$ & $\begin{array}{l}12,466 \\
(5.0 \%)\end{array}$ & $\begin{array}{l}11,885 \\
(4.8 \%)\end{array}$ & $\begin{array}{l}12,405 \\
(4.9 \%)\end{array}$ & $\begin{array}{l}12,213 \\
(4.8 \%)\end{array}$ & $\begin{array}{l}85 \% \\
\text { From } \\
1999\end{array}$ \\
\hline OxyContin & -- & -- & -- & -- & -- & -- & $\begin{array}{l}1,213 \\
(0.5 \%)\end{array}$ & $\begin{array}{c}1,226 \\
(0.5 \%)\end{array}$ & $\begin{array}{c}1,323 \\
(0.5 \%)\end{array}$ & $\begin{array}{l}1,422 \\
(0.6 \%)\end{array}$ & $\begin{array}{c}1,459 \\
(0.6 \%)\end{array}$ & $\begin{array}{c}1,677 \\
(0.7 \%)\end{array}$ & $\begin{array}{c}1,869 \\
(0.7 \%)\end{array}$ & $\begin{array}{l}54 \% \\
\text { From } \\
2004\end{array}$ \\
\hline Tranquilizers & $\begin{array}{c}1,940 \\
(0.9 \%)\end{array}$ & $\begin{array}{c}2,728 \\
(1.2 \%)\end{array}$ & $\begin{array}{l}2,731 \\
(1.2 \%)\end{array}$ & $\begin{array}{c}3,673 \\
(1.6 \%)\end{array}$ & $\begin{array}{c}4,849 \\
(2.1 \%)\end{array}$ & $\begin{array}{c}5,051 \\
(2.1 \%)\end{array}$ & $\begin{array}{l}5,068 \\
(2.1 \%)\end{array}$ & $\begin{array}{l}5,249 \\
(2.2 \%)\end{array}$ & $\begin{array}{l}5,058 \\
(2.1 \%)\end{array}$ & $\begin{array}{l}5,282 \\
(2.1 \%)\end{array}$ & $\begin{array}{l}5,103 \\
(2.0 \%)\end{array}$ & $\begin{array}{l}5,460 \\
(2.2 \%)\end{array}$ & $\begin{array}{l}5,581 \\
(2.2 \%)\end{array}$ & $188 \%$ \\
\hline Stimulants3 & $\begin{array}{c}1,489 \\
(0.7 \%)\end{array}$ & $\begin{array}{c}2,291 \\
(1.0 \%)\end{array}$ & $\begin{array}{l}2,112 \\
(0.9 \%)\end{array}$ & $\begin{array}{c}2,486 \\
(1.1 \%)\end{array}$ & $\begin{array}{c}3,380 \\
(1.4 \%)\end{array}$ & $\begin{array}{l}3,031 \\
(1.3 \%)\end{array}$ & $\begin{array}{l}3,254 \\
(1.4 \%)\end{array}$ & $\begin{array}{c}3,088 \\
(1.3 \%)\end{array}$ & $\begin{array}{c}3,791 \\
(1.5 \%)\end{array}$ & $\begin{array}{c}2,998 \\
(1.2 \%)\end{array}$ & $\begin{array}{c}2,639 \\
(1.1 \%)\end{array}$ & $\begin{array}{c}3,060 \\
(1.2 \%)\end{array}$ & $\begin{array}{c}2,887 \\
(1.1 \%)\end{array}$ & $94 \%$ \\
\hline Sedatives & $\begin{array}{c}522 \\
(0.2 \%)\end{array}$ & $\begin{array}{c}631 \\
(0.3 \%)\end{array}$ & $\begin{array}{c}611 \\
(0.3 \%)\end{array}$ & $\begin{array}{c}806 \\
(0.4 \%)\end{array}$ & $\begin{array}{c}981 b \\
(0.4 \% b)\end{array}$ & $\begin{array}{c}831 \\
(0.3 \%)\end{array}$ & $\begin{array}{c}737 \\
(0.3 \%)\end{array}$ & $\begin{array}{c}750 \\
(0.3 \%)\end{array}$ & $\begin{array}{c}926 \\
(0.4 \%)\end{array}$ & $\begin{array}{c}864 \\
(0.3 \%)\end{array}$ & $\begin{array}{c}621 \\
(0.2 \%)\end{array}$ & $\begin{array}{c}811 \\
(0.3 \%)\end{array}$ & $\begin{array}{c}907 \\
(0.4 \%)\end{array}$ & $56 \%$ \\
\hline $\begin{array}{l}\text { Marijuana and } \\
\text { Hashish }\end{array}$ & $\begin{array}{l}18,710 \\
(8.6 \%)\end{array}$ & $\begin{array}{l}19,102 \\
(8.6 \%)\end{array}$ & $\begin{array}{l}18,589 \\
(8.3 \%)\end{array}$ & $\begin{array}{l}21,086 \\
(9.3 \%)\end{array}$ & $\begin{array}{l}25,755 \\
(11.0 \%)\end{array}$ & $\begin{array}{l}25,231 \\
(10.6 \%)\end{array}$ & $\begin{array}{l}25,451 \\
(10.6 \%)\end{array}$ & $\begin{array}{l}25,375 \\
(10.4 \%)\end{array}$ & $\begin{array}{l}25,378 \\
(10.3 \%)\end{array}$ & $\begin{array}{l}25,085 \\
(10.1 \%)\end{array}$ & $\begin{array}{l}25,768 \\
(10.3 \%)\end{array}$ & $\begin{array}{l}28,521 \\
(11.3 \%)\end{array}$ & $\begin{array}{l}29,206 \\
(11.5 \%)\end{array}$ & $56 \%$ \\
\hline
\end{tabular}




\begin{tabular}{|c|c|c|c|c|c|c|c|c|c|c|c|c|c|c|}
\hline DRUGS & $\stackrel{\curvearrowleft}{\circ}$ & รั & ¿্ণ & 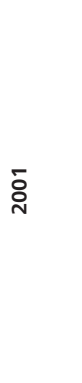 & ัิ & $\stackrel{m}{\circ}$ & ષ્రે & ๕̊ํํ & ঃั & ڤ્̀ & ర్రొ & 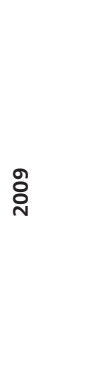 & $\frac{0}{i}$ & 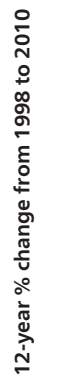 \\
\hline Cocaine & $\begin{array}{c}3,811 \\
(1.7 \%)\end{array}$ & $\begin{array}{c}3,742 \\
(1.7 \%)\end{array}$ & $\begin{array}{c}3,328 \\
(1.5 \%)\end{array}$ & $\begin{array}{l}4,186 \\
(1.9 \%)\end{array}$ & $\begin{array}{l}5,902 \\
(2.5 \%)\end{array}$ & $\begin{array}{l}5,908 \\
(2.5 \%)\end{array}$ & $\begin{array}{l}5,658 \\
(2.4 \%)\end{array}$ & $\begin{array}{l}5,523 \\
(2.3 \%\end{array}$ & $\begin{array}{l}6,069 \\
(2.5 \%)\end{array}$ & $\begin{array}{l}5,738 \\
(2.3 \%)\end{array}$ & $\begin{array}{l}5,255 \\
(2.1 \%)\end{array}$ & $\begin{array}{l}4,797 \\
(1.9 \%)\end{array}$ & $\begin{array}{l}4,449 \\
(1.8 \%)\end{array}$ & $17 \%$ \\
\hline $\begin{array}{l}\text { TOTAL ILLICIT } \\
\text { DRUGS1 }\end{array}$ & $\begin{array}{l}23,115 \\
(10.6 \%)\end{array}$ & $\begin{array}{l}25,402 \\
(11.5 \%)\end{array}$ & $\begin{array}{l}24,535 \\
(11.0 \%)\end{array}$ & $\begin{array}{l}28,409 \\
(12.6 \%)\end{array}$ & $\begin{array}{l}35,132 \\
(14.9 \%)\end{array}$ & $\begin{array}{l}34,993 \\
(14.7 \%)\end{array}$ & $\begin{array}{l}34,807 \\
(14.5 \%)\end{array}$ & $\begin{array}{l}35,041 \\
(14.4 \%)\end{array}$ & $\begin{array}{l}35,775 \\
(14.5 \%)\end{array}$ & $\begin{array}{l}35,692 \\
(14.4 \%)\end{array}$ & $\begin{array}{l}35,525 \\
(14.2 \%)\end{array}$ & $\begin{array}{l}37,957 \\
(15.1 \%)\end{array}$ & $\begin{array}{l}38,806 \\
(15.3 \%)\end{array}$ & $68 \%$ \\
\hline
\end{tabular}

--Not available

Note: 2002 to 2010 data is based on 2010 National Survey on Drug Use and Health Survey Report. a Difference between estimate and 2010 estimate is statistically significant at the 0.05 level. b Difference between estimate and 2010 estimate is statistically significant at the 0.01 level.1 Illicit Drugs include marijuana/hashish, cocaine (including crack), heroin, hallucinogens, inhalants, or prescription-type psychotherapeutics used nonmedically. Illicit drugs other than marijuana include cocaine (including crack), heroin, hallucinogens, inhalants, or prescription-type psychotherapeutics used non-medically. The estimates for nonmedical use of psychotherapeutics, stimulants, and methamphetamine incorporated in these summary estimates do not include data from the methamphetamine items added in 2005 and 2006.

2 Nonmedical use of prescription-type psychotherapeutics includes the nonmedical use of pain relievers, tranquilizers, stimulants, or sedatives and does not include over-the counter drugs.

3 Estimates of nonmedical use of psychotherapeutics, stimulants, and methamphetamine in the designated rows include data from methamphetamine items added in 2005 and 2006 and are not comparable with estimates presented in NSDUH reports prior to the $2007 \mathrm{Na}$ tional Findings report. For the 2002 through 2005 survey years, a Bernoulli stochastic imputation procedure was used to generate adjusted estimates comparable with estimates for survey years 2006 and later.

Source: Substance Abuse and Mental Health Services Administration. Results from the 2010 National Survey on Drug Use and Health: Summary of National Findings. http://www.samhsa.gov/data/NSDUH/2k10NSDUH/2k10Results.pdf [170]. Access date 2/22/2012

Table 1. Types of illicit drug use in the past year among persons aged 12 and older: numbers in thousands from 1998 to 2010 (12 years)

There is good evidence that opioids are effective, and the Institute of Medicine (IOM) does promote pain treatment with these agents, but the rapidly increasing availability of drug does 
seek justification. Opioids in the U.S. are a popular choice to treat painful complaints, with use rising from 96mg of morphine equivalents per person in 1997 to $710 \mathrm{mg}$ per person in 2010. The staggering opioid availability is equivalent to $7.1 \mathrm{~kg}$ of opioid for every 10,000 people [4]. This begs the question, is there a proportionate growth in pain and suffering? Have we undertreated pain as a legitimate affliction for decades, or are we pressured to a more aggressive care model?

Gram for gram, the U.S. consumes more opioids than any other country in the world. Despite increasing availability and distribution, limited evidence exists that effective chronic pain treatment is a reduced cost to society, or improves function. There is an abundance of evidence, however, that with this increased availability and use, increased morbidity and mortality escalates in an almost parallel fashion [5].

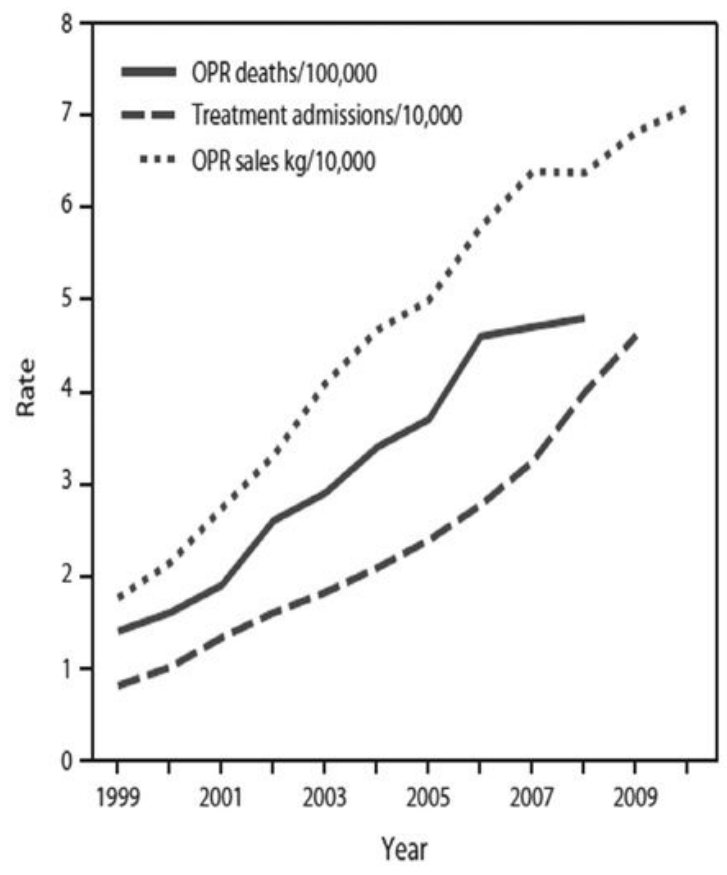

Unintentional opioid overdoses have exceeded heroin and cocaine deaths combined. Opioids contribute to 1 death every 36 minutes [6-10]. The societal impact is more complex than most providers realize. For every death, 9 patients are admitted for substance abuse treatment and 161 for abuse and dependence, with an estimated cost burden of \$20 billion [11]. Heroin has recently reemerged in certain areas of the country, presumably as opioid availability decreases. Novel combinations of fentanyl and heroin are a fatal combination.

Nonmedical use of opioids for recreational purposes is now considered an epidemic in the U.S. [12]. The inevitable catastrophe of reckless prescribing and aberrant consumer behavior 


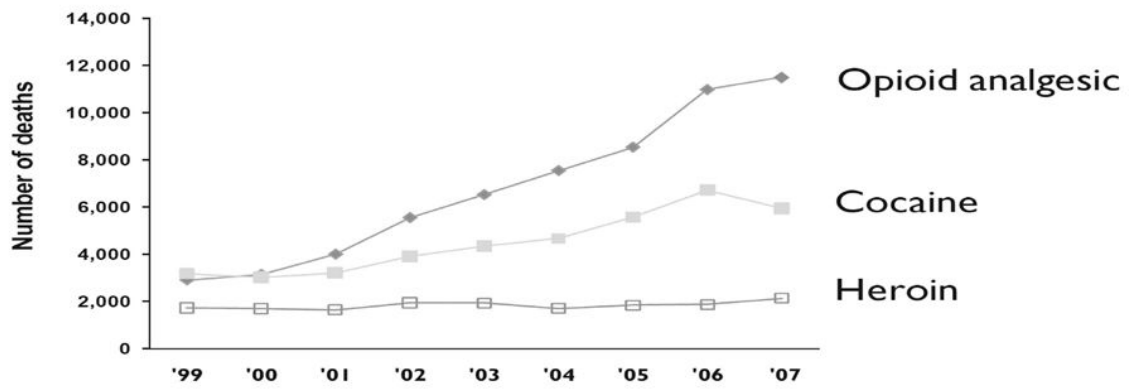

is measured by unexpected adverse consequences. This high risk behavior can result in disastrous outcomes. For every 50 people who take recreational opioids, the result is an unexpected death [13]. First observed a decade ago when emergency department visits due to opioid poisoning rose by almost five-fold, regulatory agencies remained silent. The response to this crisis has remained feeble. The perception that pain is undertreated, promoted by special interest groups and pharma, has led to an explosion of prescriptions and supply slowly being recognized as a major healthcare challenge.

According to the ARCOS data provided by the Drug Enforcement Administration, major classes of opioids have increased substantially in total grams of distribution despite the readily available data linking adverse outcome to availability [14]. In the early 1990s opioid analgesics, led by morphine, Fentanyl, Oxycodone, and Hydrocodone had significant increases in use. From 2004-2011 Hydrocodone use increased by $73 \%$, morphine $64 \%$, methadone $37 \%$, and Fentanyl 35\%. Sales of opioids quadrupled between 1999 and 2010 [15]. Hydrocodone is the number one dispensed prescription in the U.S., and the U.S. is the world leader in its consumption [16]. The most remarkable increase in use and availability was buprenorphine. Buprenorphine is indicated for the treatment of addiction and dependency, and in some cases, pain. This is the irony of controlled substance management. To control risk, the provider must be educated and vigilant in techniques to avoid dependence, misuse, abuse, and diversion. The flawed concept of dependency and addiction presents itself with buprenorphine. Buprenorphine is a substitute drug of dependency, and not surprisingly, abuse is on the rise.

The Drug Abuse Warning Network (DAWN) exists to provide information to governmental agencies about emergency department visits related to opioid poisoning. Even codeine, which is reported to have a decrease in prescriptions this decade, increased in misuse. Hydromorphone led the way with the highest increase between $438 \%$, followed by Oxycodone, Fentanyl, Hydrocodone, and Methadone. Prescription opioids revealed in DAWN data mention an increase in adverse events $4 \%$ in 1996 data to $20 \%$ in 2011 [17]. Not surprisingly, patients seeking detoxification also increased during this period. With the increasing liberalization of laws surrounding marijuana, a drug of abuse that should be treated no differently than any other molecule of abuse and misuse. This drug has also realized an increase in adverse outcomes. Marijuana is considered a safe and benign drug by a vast majority of Americans, but like any abusable substance, has risk. Unlike every other drug, the legislation of marijuana 
for medical or recreational purposes was not the doing of the FDA, but by the voter. Marijuana is a drug of consequences. It is abusable, associated with psychometric impairment and addiction. Prior to functional executive brain maturation at age 25, irreversible impairment of IQ may occur. Definable benefits to medical application are being studied. Bone healing, neuronal protection after stroke, and seizure management may benefit from a medical application. Smoking the drug to obtain THC is unmeasured and variable. Liquid variants may be superior. As the THC potency continues to be engineered and enhanced in the weed, the medical value may be diminished. THC concentration has increased from $2 \%$ in the $1970 \mathrm{~s}$ to $8 \%$ and rising [18]. Interestingly, although highly habituating, patients seeking detoxification from cocaine have decreased.

The use of controlled substances for recreational purposes or diversion was not realized as a problem to its full extent until 1996. Prior to 1996, the DAWN and ARCOS data did not reveal any particular trend in abuse, misuse, or diversion. During that same period of time, medical use of opioids was increasing rapidly, but no particular trend divulged the urgent need for increased scrutiny of these agents. Most believed that the increased use of opioids was responsible for improved treatment of chronic pain. The opposite appears to be evident. Despite mounting evidence that chronic opioid therapy does not improve quality of life, their use continues to rise [19]. Further underscoring this irony is the persistent lack of evidence supporting chronic use, and the abundance of evidence that reveals these agents are risky, and in certain patient populations, dangerous. Efforts at educating the medical community are in place, but persistent widespread use is continuing to promote misuse, abuse, and diversion. The group most willing to prescribe controlled substances is also the provider with the least amount of time to assess risk, and apply principles of adherence monitoring. Primary care physicians are responsible for the largest population of patients chronically exposed to controlled substances. It surprises many that the vast majority of opioid prescriptions are from general practitioners, family medicine, and internists. Anesthesiologists and physical medicine, traditionally associated with pain clinics, are responsible for only about $6 \%$ of total prescriptions combined [20].

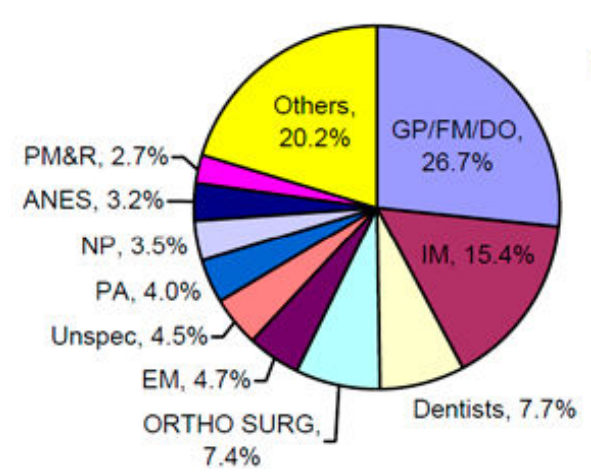

$7.4 \%$

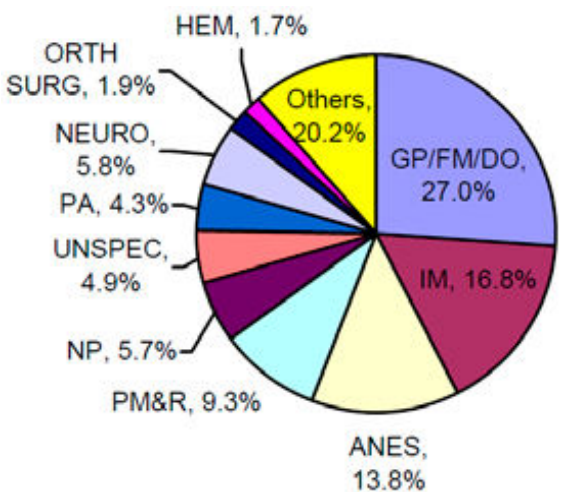

ANES, 


\section{Epidemiology}

Epidemiology is the study of factors that determine or influence a pattern in prevalence of disease or a condition in populations [21]. Healthcare spending accounts for $16 \%$ of the gross domestic product and is continuing to climb, with expectations approaching $25 \%$ of the GDP by 2025 [22]. Chronic illnesses are a major cost driver, with projected increases from 133 million in mid-2000, to 171 million in 2030 [23]. The healthcare burden of chronic non-malignant pain is enormous, and a major cost driver in chronic disease. More than $1 / 4$ of Americans suffer from daily pain at a cost of almost $\$ 60$ billion in lost productivity in the U.S. alone [24]. Those of lower socioeconomic status experience pain more often. Individuals making $\$ 30,000$ or less a year spend nearly $20 \%$ of their life in moderate to severe pain. This directly contrasts to households earning more than $\$ 100,000$ a year, which experienced pain at $8 \%$ of their life or less. Those that did not finish high school feel twice as much pain as college graduates. A number of proposed reasons for this discrepancy can be presumed. Those with lower socioeconomic status tend to have more labor-intensive work, and fewer conveniences. The type of work performed is less ergonomically appealing, and those with lower socioeconomic status tend to have more drivers of poor well health characteristics, such as tobacco consumption. It is not surprising that pain medications are a first choice in those suffering from pain, because they are easily obtainable. Americans spend approximately $\$ 2.6$ billion in over-the-counter pain medications alone and $\$ 14$ billion on analgesics as a class [25].

The burden of pain is also felt psychologically. Over a quarter of patients believe they will always have pain and there is no solution, and their doctor rarely understands how they feel. Up to $1 / 3$ of chronic pain patients have reported they received little, if any, relief from treatments or therapies. The prevalence of pain in the American population is substantial, with 4 out of 10 Americans saying they experience pain daily, which rises in the aging population approaching $60 \%$ in those aged 65 and older. 9 out of 10 Americans say they experience pain some time each month, which would increase utilization of healthcare services to be directly related to these incidences of pain. In fact, despite the prevalence of pain, nearly two-thirds see a doctor only when they cannot stand the pain any longer [26].

Pain remains one of the most frequent chief complaints in the primary care office, with $40 \%$ of primary care visits seeking relief, and $20 \%$ of those are chronic pain visits. In primary care practices, almost $15 \%$ of patients require pain medication or treatment. Up to $20 \%$ of patients in a primary care setting are on chronic opioid therapy [27].

Loss of work is a major problem related to pain. Almost $55 \%$ of the work force reports having pain the past 2 weeks and of that, almost 15\% experience lost productivity due to pain. One percent of the work force is absent from work one or more days a week, with headache and back pain being the most common complaint. Migraines are estimated to affect 30 million a year, with overall prevalence in the U.S. population approaching $15 \%$. Women are three times more likely than men to develop migraines, with peak year's incident age 25-45 [28]. Osteoarthritis, low back, and neck pain is another substantial percentage of the American population suffering from pain. $16 \%$ of the U.S. population, or almost 45 million, report pain directly related to osteoarthritis [29]. The incidence of low back pain peaks about the sixth decade of 
life, and $50 \%$ of Americans report some episode of back pain. Neck pain occurs about half as often as low back pain, and effects $10 \%$ of the general population [30].

\section{Anatomy, neurobiology, and nociceptive systems}

"The affective motivational aspect of pain originates in the periphery and suffering is not merely a matter for neocortex, it is profoundly more ancient and primitive biogenetically and is reflected in fiber tracts and neural networks throughout the nervous system." [31]

Pain is "an unpleasant sensory or emotional experience associated with actual potential tissue damage or described in terms as such tissue damage" [32].

Pain is a personal experience, and is a perception of abnormality that relies on descriptors. It is a sensory event of the peripheral and central nervous system, and is only partially defined by the initiating or traumatic event. The effects of pain at any level projects changes to the central nervous system that increase the likelihood of neurobiological changes, within nociceptive systems. The inciting pain generator becomes less relevant over time, as pain is promoted neurobiologically. As more recent understanding of these nociceptive systems evolves, it is better understood that pharmacologic manipulation is often necessary to modulate chronic pain states.

Acute pain is a symptom of a disease and is usually self-limited. It is provoked by tissue injury, not just stimulation, and is usually associated with abnormal functioning of somatic structures. This event could be secondary to emotional responses, autonomic, or a psychological stimulation and response. It has a biological function to alert and warn the individual, and also withdraw for healing and resting. Chronic pain however, sometimes can become the disease itself. It persists beyond the usual course of the acute disease. Chronic pain persists beyond tissue healing and usually is experienced over three months, or some combination therein, associated with impaired function and quality of life indices. Like many other chronic conditions such as hypertension and diabetes, treating chronic pain requires its own set of paradigms and treatment strategies. If the patient has an uncontrolled pain condition, what would normally be an eventful recovery could lead to persistent pain, and often requires chemical therapy or interventions in a multimodality approach to control the pain. Chronic pain is provoked by a chronic pathological process and can result from a dysfunction in the central nervous system. The nervous system evolves into a hypervigilant state, or "wind up", and in turn activates central nervous system elements that may provoke psychological and depressive conditions. Autonomic and neuroendocrine responses may be absent, and it is here that chronic pain is felt to alter biological function [33]. The central nervous system is being remodified to recognize the neurobiological changes that chronic pain evokes. As many of these pain pathways are intimately related with the limbic system and primitive brain structures, associated mood and behavioral changes occur. The interrelationship between the primitive brain and higher cognitive function eventually signals the prefrontal cortex that an abnormal sensation is felt. The patient is then motivated to dampen these systems, and when persistent pain is untreated, impaired restorative sleep capacity is observed, anxiety is 
detected, and situational depression emerges from these pain states. This further withdraws the patient from active lifestyle, and other somatic complaints develop as comorbidities.

\section{Nociception}

A nociceptor is normal if it hurts. The anatomic pathway, spinal thalamic tract, is activated by a peripheral nociceptor, transmitted to the dorsal horn in the spinal cord, which then progresses the signal contralaterally through the spinal thalamic tract to the brain and limbic structures. The dorsolateral funiculus, a modulating descending pathway, dampens the effect of pain at the juncture of the first and second order neuron. The second order neuron resides in a well laminated architecture, the "rexed lamina," located in the dorsal horn of the spinal cord. Here it begins, here it is modulated. At the cellular level, opioid receptors at the second order neuron, which is in the dorsal horn of the spinal cord, diminish the impact of the nociceptor stimulus.

There are two types of nerves that are relevant to pain processes. Acute pain is a fast, electriclike pain that is transmitted by A-delta nociceptors. Dull, aching, throbbing, phylogenetically primitive pain is transmitted by the C-fiber nociceptor. At the cellular level, a process of transcription and gene induction elaborates algogenic mediators of pain. The algogenic mediators may be nitric oxide, cholecystokinin (CCK), substance $\mathrm{P}$, and prostanoids, to name a few. Substance P sensitizes the CNS at the receptor site, where N-methyl-D aspartate (NMDA) receptors promote activation of ion channels in pain promoting areas.

Pain signaling, from outside in, cutaneous muscle and visceral tissues initiate high threshold chemical, mechanical, or thermal stimuli to activate neurophysiologic pathways through electrophysiological activity, and engages the second ordered neuron at the rexed lamina. Both sodium and calcium influx leads to release of calcium intracellular stores, and decreased nociceptor thresholds. When this occurs long term, the transcriptive events at the neuron may become sensitized. This is the beginning of the origination of pain, outside in, toward the spinal cord. The role of algogenic mediators of pain may lead to a number of descriptive pain states at this level, such as hyperpathia, hyperalgesia and allodynia. The type 1 and 2 A-delta fibers are small (1.1 to 5-micrometers in diameter), myelinated, and rapidly conducting (at 5 to 30 meters per second). This is a sharp electric pain. The quick retraction from a hot ember, or stubbing a toe. C-fibers, are the smaller (.25 to 1.3 micrometer diameter) unmyelinated slow fibers, ( 0.5 to 2 meters per second) that give a poor characterization of pain. These are the "second pain" transmitters that quantify pain poorly. C-fibers are considered polymodal, and are activated by mechanical, chemical or thermal mechanisms. The vague abdominal discomfort in the viscera is an example of C-fiber mediated pain, leading to vague descriptors of pain that are poorly localized in the gut. The odd finding that abdominal pain sometimes activates a discomfort in other parts of the body may be explained by the convergence of afferent activity at the second order neuron from different structures. Visceral stimulation has often been observed to incite pain in the shoulder. When adrenergic receptors are activated, peripheral autonomic dysfunction, and sympathetically driven pain may emerge. Ultimately, these 
sympathetic changes are manifested in pseudomotor changes, and are revealed as the progressive alterations in the periphery, such as seen in complex regional pain syndrome (CRPS).

Once converged at the dorsal horn, the A-delta and C-fibers synapse at laminae 1-2, 2A, and 5. At the dorsal horn, a complicated and coordinated activation of many of the important cascade elements that promote pain occur. Glutamate activation of the AMPA receptor induces a sodium current and depolarization, with sustained activation of the NMDA receptor. Proteins and synaptic elements are influenced by brain derived neurotrophic factor (BDNF), inducing cellular translational events. The cascade of neurogenic inflammation is begun at the C-fiber with release of substance P, CGRP, and the resultant algogenic mediators of pain. The A-delta and C-fiber synapse with the wide dynamic range nociceptive fibers and increase the sensation of pain by a process of "summation" which amplifies pain. With repetitive noxious input, the WDR neuron is engaged in "wind up" and remain sensitized.

Ultimately, the spinothalamic tract interacts with higher centers directly approximated with many important nuclei, and deep brain structures. The "personality of pain" is directly affected by the transmission of brain through these intermediary relationships. Serotonin and norepinephrine is intimately related to these pathways. Some serotonin receptors seem to be upregulated with persistent pain stimulation. Dopamine and dopaminergic pathways in the primitive brain structures are directly affiliated with the emotional and behavioral aspects of pain. At many points through the periphery to the dorsal root ganglion, rexed lamina, as well as ascending and descending pathways, opioids have a strong influence on analgesia and the behavioral aspects of pain. Once pain is interpreted by the higher conscious state, memory and behavioral influences are introduced. Pain is a global experience, with limbic system engagement, prefrontal cortex, and primitive brain structures motivating an individual to seek relief.

Of the four types of pain - somatic, visceral, sympathetic, and neuropathic pain - somatic and visceral are nociceptive pains. Neuropathic and sympathetic are non-nociceptive. The nociceptive pain from stimulated receptors is normal if it hurts. The non-nociceptive pain rises from central nervous system and peripheral nervous system dysfunction. There are no pain receptors in this type of pain, and therefore it is caused by a dysfunctioning nociceptive system. Somatic pain, or more commonly musculoskeletal pain, is sharp and well localized. The type of pain that would be termed nociceptive or visceral are opioid responsive. Choosing the type of medication treatment for different types of pain requires an understanding of the type and described pain.

\section{Scope of problem}

The Institute of Medicine has published a report that reveals 116 million Americans suffer from pain that persists from weeks to years [34,35]. The estimated financial impact is up to $\$ 635$ billion per year in the U.S. [36-38]. It would seem logical that treating pain with an opioid strategy would diminish this staggering number, when in fact there is very little evidence that the desired relief and productivity is returned with these agents. Contrary to intuition, 
evidence suggests the alarming trend in misuse, abuse, and diversion overwhelms most potential benefits of chronic opioid use, and might argue against chronic exposure. As regulatory restrictions relaxed in the 90s, the trend to prescribe opioids increased alarmingly. Based on the patients self-report of pain, this subjective report is frequently the only tool provider's use to initiate treatment deemed chronic in nature. It was erroneously assumed that the humane approach to addressing a chronic pain condition was to prescribe an ever increasing load of opioids and adjunctive medication. Evidence is lacking in non-cancer pain that pain conditions improved as the dose escalated. Opioid-induced hyperalgesia, endocrine disorders, and the potential for poisoning highlight the better conservative course of care, supporting a more conservative contemporary decision making. The current trend in chronic pain care does not seem to reflect this approach.

The National Survey on Drug Use and Health (NSDUH), under the sponsorship of The Substance Abuse and Mental Health Services Administration (SAMHSA) is distributed to Americans from age 12 and older. Not surprisingly, marijuana is the most commonly used substance with 17 million current past month users, followed by pain relieving drugs. SAMHSA 2012 identified marijuana as the leading drug of abuse in first time users aged 12 and older. Marijuana is considered a gateway drug, and increasingly destigmatized. A staggering 38 million in 2010 used illicit drugs, which is 15\% of the American population. Nonmedical use of psychotropic therapies from 1998 to 2010 exceeded marijuana, and is ten times that of cocaine [39].

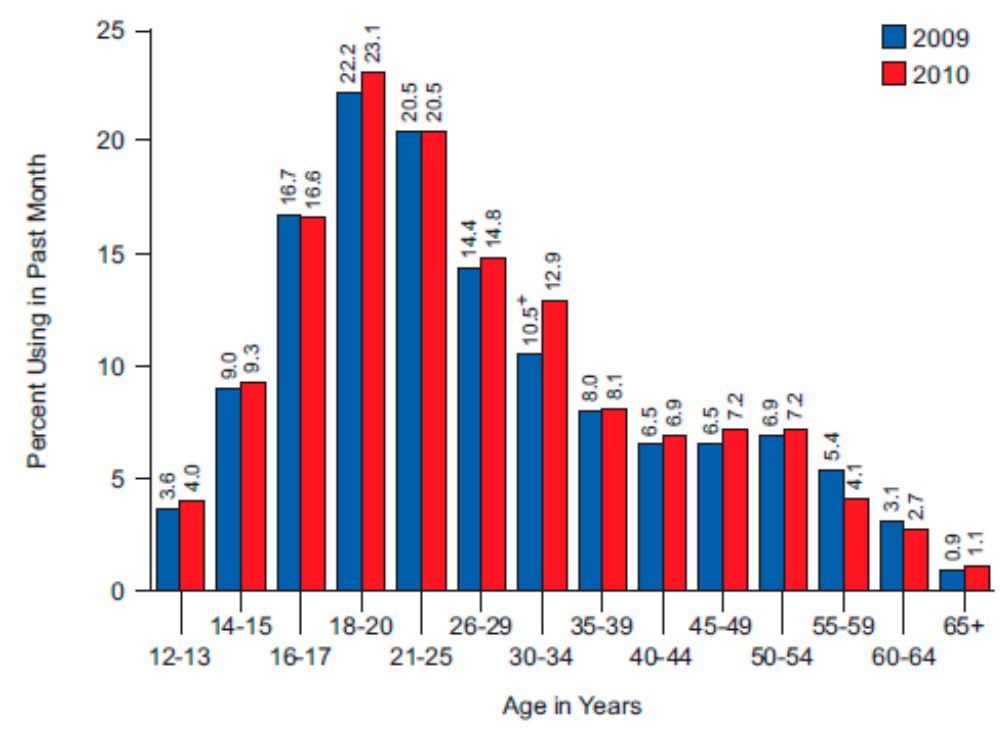

${ }^{+}$Difference between this estimate and the 2010 estimate is statistically significant at the .05 level. 


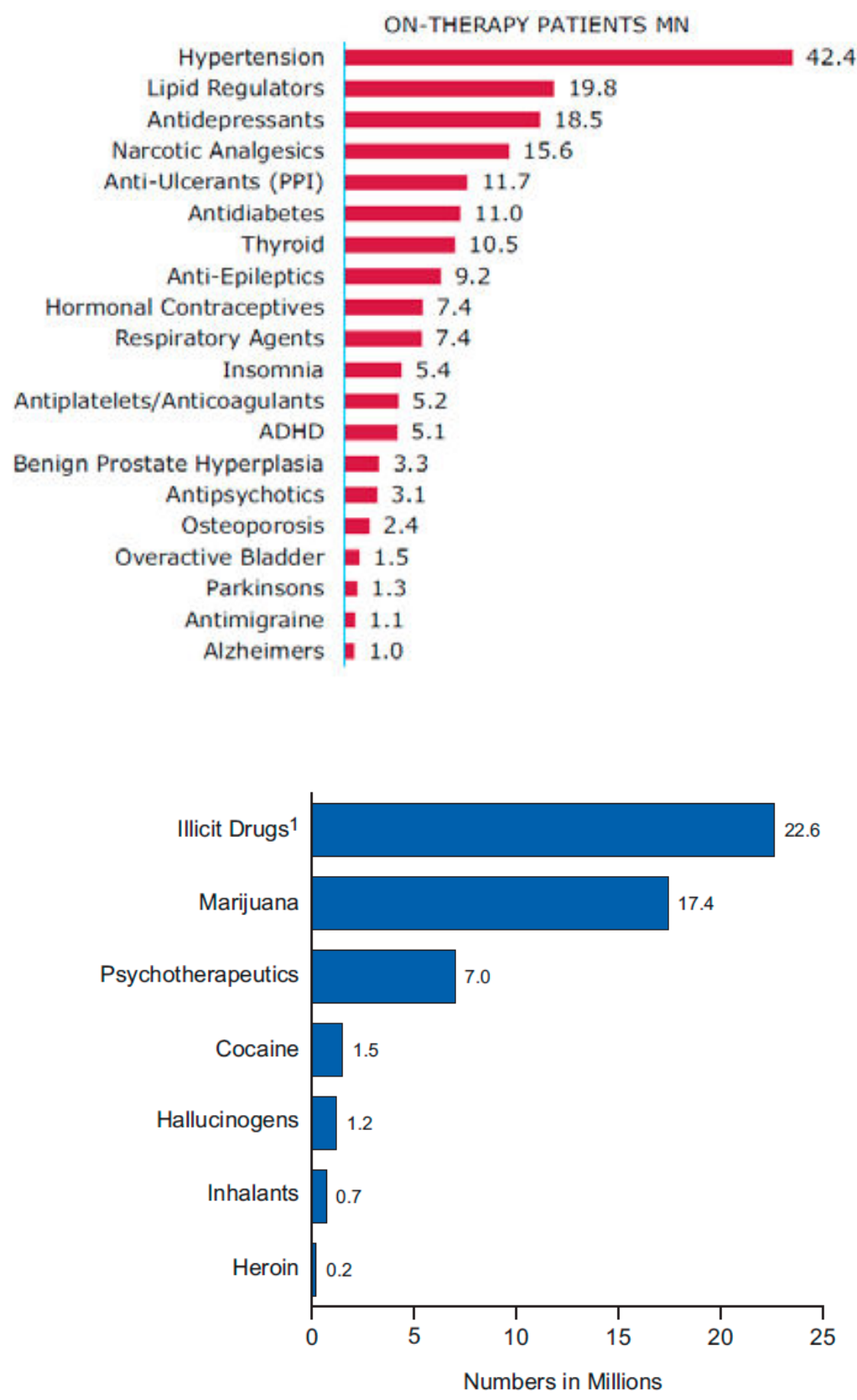

\footnotetext{
${ }^{1}$ Illicit Drugs include marijuana/hashish, cocaine (including crack), heroin, hallucinogens, inhalants, or prescriptiontype psychotherapeutics used nonmedically.
} 
The prevalence of those complaining of pain is staggering, estimated to be upwards of 100 million Americans (IOMPPT). Conversely, the incidence of diabetes registers at 25.8 million, heart disease 16.3 million, cardiovascular accidents 7 million, and all cancers combined at 11.9 million (ADA, AHA, ACA) [40]. With the prevalence of pain affecting roughly 1 in 4 Americans, there is little question why a suffering individual would seek any form of therapy, including opioids, to treat chronic nonmalignant pain. Most unfamiliar with interventional pain medicine or other options to treat their pain feel that there is only a pharmacologic solution. This multimodality approach is often underutilized to reduce opioid use. If it comes from a doctor, patients believe opioids must be safe. A report by Russell Portanoy and Kathleen Foley in 1986 opened the door to the subsequent belief that opioids are safe and have little consequences. The paper titled "Chronic Use of Opioid Analgesics and Nonmalignant Pain: Report of 38 Cases" opined that opioid maintenance therapy can be a "safe, salutary, and more humane alternative to options of surgery or no treatment for those patients with intractable nonmalignant pain and no history of drug abuse" [41]. Further supported by the historical facts that opioids have been used for thousands of years, and referenced in ancient writings, the use of opioids found a natural segway into a cost-effective and humane prescriptive environment. The first steps of an epidemic were born.

All but uncontrolled until the Harrison Act of 1914, there was little regulatory restriction on narcotics (controlled substances) in the United States. After the occupation of the Philippines in 1912, and the resultant Hague Treaty, the American response to the concern of British domination of Chinese opium trade resulted in enhanced law enforcement that had very few options to curb opioid use and the potential for misuse [42]. The rest of the world was not quick to adopt or enforce regulation, and until 1961 there were no regulations that addressed worldwide production and distribution of narcotics. The Controlled Substance Act of 1970 was a first step to address these concerns when "no relief or cure is possible, or none has been found after reasonable efforts to legitimize opioid/controlled substances prescriptive purposes." Steadily over the past few years, with advocacy and patients' bill of rights, medical societies support, and the generation of a perceived fifth pathway of pain control in the community, opioid use escalated. The National Vital Statistics Office has seen a steady rise in opioid prescriptions. Available opioids have realized a threefold rise from the late '90s. If pain relievers and tranquilizers were mixed together, as often is the case, the combination would significantly exceed marijuana use. Cocaine and heroin use remain far behind. This underscores the quadrupled death rate from 1999 to 2010. The patients really haven't changed that much, but the exposure to opioids has. [43]

Technology has given us the opportunity to identify and track prescriptive habitry, as well as patient behaviors. With any sharing of sensitive medical information, controls should be in place to assure that the proper individuals have access to the data, and HIPAA integrity is enforced. One of the major questions posed by recent efforts of accumulating patient data electronically is the question of narcotic misuse patterns by the patient, and the potential for inappropriate distribution by pharmacies and physicians. Patient data systems throughout the United States address these questions in different manners. Some embrace the access of law enforcement, others strictly prohibit information exchange to only 
providers, unless the power of the subpoena is in place. Both have pros and cons. Furthermore, physicians, extenders, dentists, pharmacies and others that prescribe are not required to access this database. The question of poor standard of care is introduced when the potential for harm exists. An overly relaxed due diligence by the prescriber or dispenser is to ignore this important technology.

In 2005, George Bush signed into place the National All Scheduled Prescription Electronic Reporting (NASPER) program which would cross state lines and provide a database to reduce cross state seeking and opioid distribution activity [44]. NASPER remains to be funded, and was ahead of its time when introduced. The current climate of opioid of misuse, abuse, and diversion underscores the need for such a program. The American College of Physicians supports NASPER, as well as other organizations, such as the founding organization of this piece of legislation The American Society of Interventional Pain Physicians (ASIPP).

Americans consume a remarkably large percentage of opioids prescribed worldwide. As a leading country in consumption, the United States only makes up $4.6 \%$ of the world's population. The U.S., however, consumes $80 \%$ of the world's available opioids. The most common opiate prescribed is hydrocodone, which the United States consumes $99 \%$ of the world's distribution of this drug. 34.2 million Americans greater than age 12 can claim use of opioid for nonmedical use at some time in their life [45]. Nonmedical use of opioids is staggering. According to DAWN data, 425,000 emergency department visits in 2010 were a direct result of nonmedical use of opioids [46]. With more than 39,000 Americans dying from drug poisoning in 2009, over 14,000 of those were from prescription opioids. But that is just a small component of the problem. For each one death there were 10,000 admissions for abuse, 32 emergency department visits for misuse or abuse, 130 who abused the drug or are addicted, on top of 825 nonmedical users for recreational purposes [47]. With such ready availability and willingness to use opioids perceived as "safe", the stigma of controlled substances is removed. In the medicine cabinet, the risk of street drugs is not a factor. Cocaine, heroin, even marijuana has a supplier for distribution of unknown character, and the drug is always of unknown origin and purity. Not so with controlled substances, regulated by the FDA. The danger, however, is real. Each passing year for the past fifteen, the opioid death rate, opioid treatment admissions, and kilograms sold is in parallel progression with the availability.

Opioid analgesic deaths exceeded cocaine and heroin deaths at an ever-increasing rate since 1999. Cocaine deaths are actually decreasing. Recently, heroin deaths have increased, but still remains one-sixth that of opioid analgesics. Methadone is one of the cheapest and readily available opioids, and is one of the leading drugs responsible for opioid fatalities. Methadone is just $3 \%$ of opioid prescriptions in the United States but is associated with $>30 \%$ of deaths from opioids [48]. This staggering relationship could be attributed to methadone's unpredictable metabolism and half-life, and the numerous drugs that interact with methadone metabolism and excretion. 


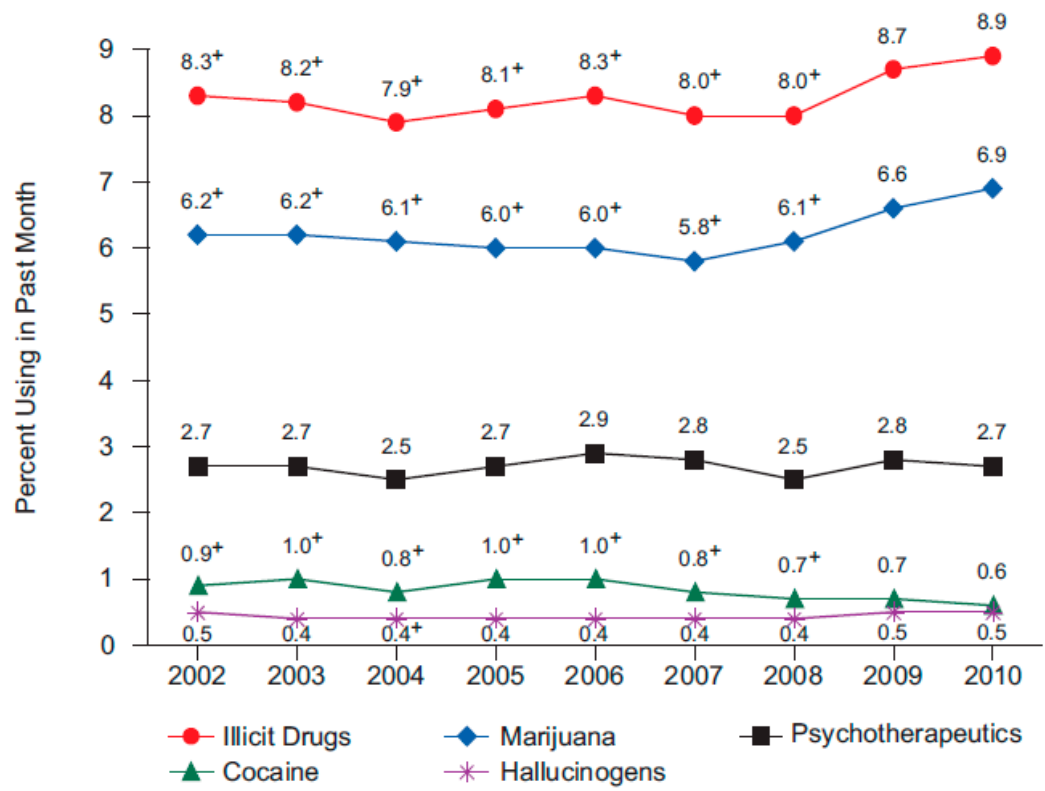

+ Difference between this estimate and the 2010 estimate is statistically significant at the .05 level.

\section{The evidence}

The diversity of chronic pain conditions is extensive. Pain complaints range from headache pain, spine pain, abdominal pain, myofascial pain, to extensive undefined widespread discomfort. Chronic nonmalignant pain is rarely a single diagnosis. There is evidence that controlled substances are helpful to control symptoms, improve function, and quality of life. There is good evidence that opioids are strong analgesics, and have a role in chronic pain management.

There is also extensive evidence that controlled substances are responsible for misuse, abuse, and diversion. Particularly concerning is the concept of diversion. The DEA introduces a mixed message to prescribers treating those with pain. First, the DEA is responsible for the availability of the drug and will acknowledge that the physician is best prepared and trained to determine whether opioids are indicated. The DEA will further point out that the physicians are at risk for providing these medications, and may be unwittingly providing controlled substances to inappropriate recipients. The word recipient is used over patient as often is the case of those seeking drugs for distribution. These diverters are neither a patient, nor have a truly justifiable chronic pain condition that would warrant controlled substances. If a physician is a partner in diversion, knowingly or not, law enforcement has the option to prosecute.

- SS 841 knowingly or intentionally distributing or dispensing a controlled substance 
- No legitimate medical purpose for the prescription in that the same was not issued/filled in the usual course of professional practice or was beyond the bounds of medical practice

- The conviction will be upheld even if the government does not present compelling evidence that the doctor prescribed with malicious motive or the desire to make a profit

- Abbreviated or no medical history of physical examination is probative on the question of whether a legitimate medical purpose exists

Prescribing to an individual with a nefarious purpose, even if you are unaware, may implicate the prescriber and result in a legal action. The provider does not have to know, or profit from the encounter. It simply has to happen. So the benefits of analgesia and improved function and quality of life are now weighed against the abuse risk, misuse, and addiction threat. The epidemic of chronic pain, its treatment with opioids, and the parallel morbidity and mortality compels the prescriber to utilize all tools available to ensure that the proper prescription is given to the proper individual for the proper purpose. The implications of this standard are far reaching. Increased scrutiny can now be placed on individuals who prescribe beyond their scope of care. An example might be an ophthalmologist providing diet pills to his mistress [49]. To the busy family practice physician that has not exercised proper caution, and only performs a brief history or physical that does not support opioid use in the documentation, the risk/ reward benefit does not fall in the practitioner's favor. It is not necessarily the intention to provide substandard care, but time pressures are very real and patient needs and demands can be extensive. A patient or individual that is persistent in aggressively obtaining controlled substances knowingly does so against the physician's common daily practice paradigm. Most physicians are ill-equipped to confront a patient that exhibits inappropriate pain behaviors and drug seeking activity. In some cases, a level of fear and bullying is injected into the practice from a patient that is highly motivated to obtain a controlled substance. Evidence exists that a physician is most likely to be non-confrontational, and accommodating, to diminish conflict. This would include writing a prescription as the most expeditious and safest way to remove this patient burden. Deyo, et al reported $61 \%$ of patients with low back pain in primary care settings were on opioids at one point in the course of care [50]. Almost 20\% of these were longterm users in the primary care setting. Primary care physicians are the most common prescriber of opioids, followed by surgical specialties. Primary care providers are also the source of most immediate-release opioid prescriptions. Despite limited evidence that effective chronic pain care therapy is enhanced with short-acting opioids, these highly abusable agents are commonly prescribed [51]. Numerous guidelines also point out that long-term exposure to opioids is of questionable benefit, with only small to moderate improvements in most pain states. By contrast, evidence exists that poor patient selection is a leading cause of adverse outcome when opioids are utilized to treat painful disorders [51].

Another concern regarding controlled substances, opioids in particular is the milligram dosing the patient is exposed to. A group in Washington State recommends the dosing equivalent not exceed 120mg of Morphine [52]. Proponents of education emphasize proper prescription habits to realize establishment of medical necessity, which isn't always obvious. Once need is established, identifying the risk of misuse, abuse, and diversion, and utilizing strategies to mitigate risk is good medical practice. 
Another important concept is acknowledging the multimodality approach to dealing with pain, and subsequently reducing the opioid load. It has been demonstrated that interventional techniques do address this concern and can reduce or eliminate the need for controlled substances.

The typical patient referred to a pain management physician either comes from a surgical referral or a primary care. As stated earlier, primary care is responsible for most opioid prescriptions and often patients expect that opioid therapy will remain stable and be continued at the current dosing. Over time, the patient develops a number of expectations as to entitlement of these drugs. Frequently referred to as "my hydros" or "my Oxys" for example, a high level of anxiety is demonstrated when patients are educated about dose reduction, and exit strategies from opioid-based therapy. This is an "opioid" stress test. Aberrant personality behaviors can be confrontational, and emotional. Sometimes threats are made, and retaliation may use the anonymity of social media, criticizing the physician in the numerous online rating services, and even reporting the provider to the medical board. These retaliatory activities are a demonstration of inappropriate illness behaviors, and reveals that the patient was a poor choice for long-term opioid therapy. There is some truth to the belief that a good pain management provider, with skill at controlled substance management, will have poor ratings in social media and other physician rating services. The sad but true irony is that patients read these online ratings, and make ill-conceived judgments about the individual provider, or the care they have been rendered, owing more credibility to the rating sites than the patient/ physician relationship. This is a new form of physician slander, and there is virtually no response that a physician can muster to defend their reputation. There is good evidence this retaliation occurs.

Patients with non-cancer pain treated in the non-specialist's office are often referred without benchmarks. Benchmarks are understanding the benefit risk ratio of opioids and treatment strategies at 3, 6, 9, and 12 months. These benchmarks should be straight forward and easy for the patient to realize, with documentation to the medical record in the form of function and quality of life indices. The patient might describe his/her benchmarks as simple as walking $1 / 4$ mile at 3 months four times a week, or even consider advanced lifestyle changes. Within these benchmarks, the concept of the exit strategy is defined. This eliminates the misunderstanding that opioids are an indefinite life treatment expectancy. There is no barrier to communication, and documentation in the medical record is an aid to better understand treatment efficacy and direction, demonstrating progression or regression over time.

With the initiation of opioids, there is a true and defined legitimate medical need, carried by a diagnosis, supported by diagnostics, and usually physical exam findings. As subjective as chronic pain can be, there are many tools available that document function and quality of life indices, and ultimately the true effectiveness of a treatment profile. If opioids render little help in improving movement forward in these benchmarks, or if benchmarks are never even considered, it is difficult to justify continued opioid exposure. If the risk/reward benefit of opioids is poorly documented, and the patient makes very little progress with poor lifestyle choices, ultimately opioids are of little positive value. A patient may be unable or unwilling to make an effort to change modifiable features in their health profile, and therefore it makes 
little sense to continue what is most likely a failed treatment paradigm. The multimodality tools available, such as cognitive behavioral therapy, interventional techniques, durable medical items, and advancing forward functional enhancements should have a tangible result. If the goal of the patient is just to obtain a pill, it is unreasonable to expect significant improvement at 3, 6, 9, or 12 months, and may signal inappropriate illness behaviors. There are exceptions to each treatment plan. It is reasonable to allow flexibility with pain complaints as there are multiple factors involved in the complex nature of chronic pain, where the diagnosis rarely stands as a singular complaint. The goal however, is to be clear with the patient that there is a plan. Consequences exist for the provider and for the patient if the plan is not realized, and efforts to move forward ultimately fail. The patient comes to the physician for thoughtful care, not just obtaining a prescription every month.

\subsection{Recent studies supporting opioid therapy}

Different combinations of opioids can add energy to effectiveness in the properly chosen patient. A recent long term (52 week) study revealed sustained relief with 2 different opioid preparations in patients with chronic non-cancer pain.[53] This study did not include a placebo group but it did demonstrate sustained pain relief over a longer period of time than previous studies. Another randomized trial of two opioids versus placebo has shown superior pain relief with both active analgesics for chronic knee pain. [54] Newer agents are associated with less drug liking, and the potential for abuse. Tapentadol has been reported to be superior to oxycodone for osteoarthritis pain in terms of worker productivity and cost. Tapentadol is available in $50 \mathrm{mg}$, $75 \mathrm{mg}$ and $100 \mathrm{mg}$ doses. The starting dose is 50-100 mg every 4-6 hours. The maximum daily dose is $600 \mathrm{mg}$ /day. [55] The abuse-resistant technology, Intac $\AA$, reduces the diversion potential as well. Buprenorphine transdermal has been compared to oxycodone over a 12-week period. A higher dose of buprenorphine (20 micrograms/hour) has been demonstrated to be superior to oxycodone and low dose buprenorphine ( 5 micrograms/hour). [56] Buprenorphine/naloxone sublingual film comes in $2 \mathrm{mg} / 0.5 \mathrm{mg} .4 \mathrm{mg} / 1 \mathrm{mg}, 8 \mathrm{mg} / 2 \mathrm{mg}$ and $12 \mathrm{mg} / 3 \mathrm{mg}$ doses. It is important to note that naloxone does not reverse non-opioid associated respiratory depression and sedation that might occur with barbiturates, alcohol, or benzodiazepines.

\subsection{The growing argument against chronic opioid therapy}

Numerous recent studies have reported several problem areas react with chronic oral opioid therapy. [57] Overdoses have increased significantly and are related to high doses and prolonged duration of treatment. Opioids for arthritis pain have been associated with increased risk of fractures [58,59]. The reason for this association is unknown. The DAWN data teaches us that chronic opioid therapy is associated with increased emergency room visits. Increasing opioid dosing has also been associated with increased risk of trauma in automobile accidents. [60]

Among our military veterans, post-traumatic stress disorder and opioid therapy have been associated with poor outcomes in veterans with chronic pain. [61] 
CLINICAL VIGNETTE. A 33 year old male arrives in the clinic late, claiming "car trouble." The individual has been asked to produce medications for a pill count, and a urine drug screen is planned. This is a part of normal clinic operations. A previous attempt at having the individual arrive for a pill count was thwarted when a family member died and services were attended out of state.

Pain described is sharp electric-like pain, in a non dermatomal distribution, right leg predominant. Some left arm pain, and some paracervical discomfort is evident. Further descriptors of the pain are vague and nonphysiologic. Pain is migratory, and often associated with back pain and headaches. There is no neurological deficit and no focality.

This type of vague pain pattern reveals no specific characteristics which a diagnostic platform can evolve. Often these pains are described as "myofascial or fibromyalgic." A type of pain that is poorly characterized and exaggerated, often inconsistent with examination findings. In this particular case, according to the patient the only that helps the pain is Oxycodone, and a specific dose is requested, "30s".

When treating any type of pain, a diagnosis must precede a clinical pathway. In this particular case, the only treatment that helps is an opioid-based pain medication in a young individual, with very poorly characterized pain. Because it is migratory, and nonspecific, an interventional procedure would have limited value. Allowing for age, and the lack of specific diagnostic findings, suggests this pain is better treated with non-narcotic medication alternatives. The pain described shares some characteristics of neuropathic pain and somatic character. A generalized pain treatment plan would include medications that would have minimal habituation potential, and poor drug "liking." Gabapentin or Pregabalin would be a good choice and could potentially diminish the central nervous system contribution assisting the myofascial component, and carries minimal risk of misuse, abuse, or diversion. Drugs such as Gabapentin and non-narcotic medication alternatives are also a good stress test. A patient that is seeking for a specific drug therapy is challenged to try something new, and this care is clinically sensible with less risk. If aberrancies evolve, the stress test would be positive.

Evidence suggests the alarming trend in abuse, misuse, and diversion overwhelms the most powerful benefit from chronic opioid use, and argues against chronic exposure. As regulatory restrictions were relaxed in the '90s, the trend to prescribe opioids has increased alarmingly. Based on the patients self-report of pain, it is frequently the only tool we have to identify of chronic nature. The humane approach when addressing a chronic pain condition was felt to prescribe ever increasing milligram equivalents of opioids, as well as other adjunctive medication. Evidence is lacking in non-cancer pain that pain conditions and function treated with opioids actually improve when chronic in nature. Opioid induced hyperalgesia $(\mathrm{OIH})$, endocrine disorders, and potential poisoning highlight the better course of care that stress nonnarcotic options and minimize opioid exposure [62]. Specifically, an exit strategy should exist when opioids are prescribed. If this is not always practical, benchmarks are usually a strong predictor of positive or negative outcome. 
Obesity, depression, multiple symptoms and etiologies of chronic pain are predictors of poor long-term outcomes for patients with chronic pain who are continued on chronic opioid therapy. [63]

Additional risk factors related to poor outcomes for chronic pain patients have been reported and include opioid use, older age, female gender, anti-social personality, government disability, and severe disability at initial evaluation and not working at discharge. [64] Furthermore, opioid prescription for longer than 7 days has been reported as a risk factor for long-term disability in workers with acute back pain. [65] The threshold to prescribe opioids in the primary care setting is low, particularly with vague diagnosis states and external pressures. Those that are treated with opioids for chronic pain often request ever increasing doses.

A 52-week study showed no major outcome difference between patient groups treated with a stable opioid dose regimen versus an escalating opioid dose regimen. This suggests that higher doses are not associated with additional benefit. Notably, $27 \%$ of the subjects in this study were discharged due to misuse. [66]

Several studies have demonstrated significant analgesia with opioids for chronic pain, the magnitude of pain relief is $20-30 \%$. However, $20-30 \%$ improvement is the same range as the response to tricyclic antidepressants, gabapentinoids, duloxetine and tramadol. The functional improvement associated with this analgesia is variable. Functional improvement is associated with rehabilitation treatments such as interdisciplinary care; however, interdisciplinary treatment is often not associated with pain relief. A weakness of many opioid studies is the duration of therapy. The longest randomized, placebo controlled trials are weeks in duration rather than months or years, which is often the duration of treatment with opioids used in chronic pain. Also, patients are excluded from studies if they have psychiatric problems including addiction.

Diversion of prescribed opioids is a known problem, particularly among younger patients. No validated risk assessment tool exists and no failsafe way to prevent diversion has been found that resolves or eliminates this risk. The risk of addiction is real. In a study of patients in treatment for opioids, 39\% reported being addicted to prescription opioids before switching to heroin. [67]

Addiction and abuse are related problems that are often overlooked. The acute care setting of a primary care office is a high risk environment to avoid this consequence.

\section{Clinical vignettes}

A patient presented to a pain center reporting a history of chronic pain secondary to brachial plexus avulsion. He fully availed himself to all diagnostic and treatment modalities that failed. The final treatment recommendation was a dorsal root entry zone radiofrequency ablation. When advised that no guarantee of pain relief was made, he elected to continue opioid treatment. He requested a letter supporting the prescribing of opioid for his condition. He used the letter to secure prescriptions from multiple physicians. 
Lesson learned - urine drug screens may not detect multiple prescribing sources.

A patient with complex regional pain syndrome reported relief from 6-4 mg Hydromorphone tablets every four hours. He stated he could get more relief from 7 tablets. A urine drug screen showed marijuana and it was learned that he had obtained opioids from 150 physicians and was eventually indicted on criminal charges related to selling prescription drugs. Then the patient was reported to be deceased. When law enforcement officers go to his home, the patient answers the door.

Lesson learned-urine drug screening is a useful part of an initial evaluation of patients who report current opioid use.

A new patient was admitted to the hospital with a history of pancreatitis. The patients' medical history included being treated by a physician in another state with Hydromorphone $4 \mathrm{mg}$ and took 2400 pills per month in addition to high doses of long acting oxycodone. The prescription was confirmed by a phone call to the dispensing pharmacy. The patient was treated with an intravenous PCA pump and used minimal doses without any withdrawal symptoms or pain escalation.

Lesson learned-The street value of prescription opioids is significant and physicians must develop "street smarts" in order to avoid being duped into prescribing for patients who are taking enough opioid to have a positive urine drug screen but selling the rest of their prescription as a means of financially supporting themselves. Quantitative and qualitative drug testing on admission is important before opioids are administered by the emergency room or hospital.

\section{Adherence monitoring and the concept of accountability}

As with any treatment plan, there are heralding moments in a patient's course of care that requires definitive action. Medical decision making in chronic pain is not always straight forward. There is a strong subjective interpretation of the complaint, and the supportive evidence of disease is not always visible. When the provider defines the need to initiate opioid therapy or controlled substance management, any one of a number of findings could be entered into a complex differential diagnosis. Often patients with pain suffer from situational anxiety depression, and poor restorative sleep patterns. Comorbid disease states are the norm and not the exception. Home and lifestyle intrusions involve many members of the patients surrounding environment, with a psychosocial component that is often as complex as the painful entity being treated. Formal and informal risk stratification may involve opioid risk tools, historical precedent such as criminal history or misuse, abuse and diversion history, and is documented at early stages in a patient's encounter. The medical history or the Physician State Drug Monitoring Programs (PDMP) might reveal a story of multiple prescribers, multiple prescriptions, and pharmacies [68-72]. These red flag incidences underscore the need for the previously mentioned "plan". Benchmarks that affect the patients function and quality of life status act as a strong director of care and compliance, as well as the willingness to be actively involved 
in wellness to modifiable features and health profile. Adherence monitoring tracks conformity and a patient's willingness to follow principles and policies of controlled substance management. Ongoing adherence monitoring is time consuming and labor intensive. Often the patient is introduced to the practice from primary care offices that are overwhelmed by the opioid load and patient behavior, and given just enough medicine until the patient arrives for the appointment. The false belief that this is less risky from an administrative position adds further complexity to the first encounter. The patient expects that prescriptions will be written. The provider must establish a relationship from in-depth historical investigation which can take time. The appropriate patient for opioid therapy, or one that is at high risk, requiring an elevated level of adherence monitoring, is decided early in the relationship. These are a new set of rules for the patient, underscored by a patient care agreement, understood by the patient, with no barrier to communication. This accountability and expectation requires the patient/ physician relationship to grow in trust, and these actions should not be seen as an intimidation, but more of a "universal precaution" [73]. As much as we have employed universal precautions for blood borne pathogens, we apply these principles to opioid risk intolerance. Every patient that receives controlled substances is at risk for misuse, abuse, and diversion. The unique patient population of an individual practice will best define what benchmarks are needed, what precautions need to be taken, and when the patient is held to task. Also in place are positive reinforcement scenarios, to help the patient understand that this is a part of what is routinely done in the clinic, and necessary. A process of resolution is in place if the patient deviates from the treatment plan, or presents a challenge with aberrancies or red flags in controlled substance management. As previously mentioned, an opioid exit strategy may be introduced from the very beginning of the relationship so that there are no misunderstandings. Particularly true in painful states such as fibromyalgia, and vague musculoskeletal complaints such as "low back pain", opioids are not always the best choice. Other adjunctive medications and non-narcotic options will decrease the opioid load, and many times increase relief cycling and compliance.

The process of adherence monitoring is a directed care approach to ensure that the patient receives the medication needed, in the dose necessary for therapeutic benefit, and that legitimate need is met. The components of legitimate medical need, or necessity, are a community standard, and not set by the DEA, or other regulatory agencies. Most agree that legitimate need is intuitive, but nonetheless requires careful documentation.

Another principle of adherence monitoring is defining the diagnosis. Within the expected activities of a history and physical, the formulation of a diagnosis evolves. In those that suffer from chronic pain, the diagnosis may be very straight forward such as a herniated nucleus pulpolsus (HNP), or as vague and challenging as interstitial cystitis, abdominal pain, myofascial pain, or headaches. The patient usually has pain that can't be seen, touched, felt, or measured and challenges the definition of legitimate medical need. Functional assessments, impairment of activities, and the life experiences are documented to support clinical assumptions. When opioids are introduced, the diagnosis often defines the length of exposure to an agent and the expected opioid load. An HNP may be considered correctable or not, and a headache may be cyclical or transient, and very real but invisible problems such as a traumatic 
brain injury or cluster migraine have driven some to suicide. Whatever the diagnosis, the record will reflect a level of support for that diagnosis that further legitimizes the need for opioid therapy. Risk is also assigned early, simply as low, medium or high defined by individual practitioners tolerances and training. If the patient experiences surgery, such as those that have isolated discogenic pathology, an exit strategy from opioids might be sooner than the individual that has a recurrent or persistent painful disorder such as CRPS. Individualized therapy requires documentation that exceeds a line or two of "I think it therefore it is". Once opioid therapy is initiated, as diagnosis directed, adherence monitoring begins.

Adherence monitoring is a complicated process of laboratory assessment, physical pill counts, database interrogation, and good judgment. Ultimately, the provider and patient realize a safer care environment.

\section{Drug testing}

There are four commonly utilized forms of drug testing - urine drug screening, specific drug analysis, blood, hair sampling, and saliva testing. Drug detection periods can be in the minutes to hours in blood, and similar with saliva. Urine is detected sometimes within minutes, and lingers for many days. Sweat is similar, whereas hair might be detected hours through months. Drug testing is not screening. Screening is a word that does not define necessity, which is required for testing. The purpose of adherence monitoring, including drug testing, is to strengthen the patient/physician relationship built on trust. Another purpose of urine drug testing is to identify if the patient is taking medication prescribed, or not prescribed, and as directed. Of the choices, urine drug screening is considered the gold standard. The results are a product of the dose, metabolites, type of test used, characteristics of the drug, cutoff levels, and the frequency of use.

\begin{tabular}{ll}
\hline Drug & Duration \\
\hline Amphetamine & $2-4$ Days \\
\hline Methamphetamine & $2-4$ Days \\
\hline Barbiturate & $2-30$ Days \\
\hline Benzodiazepine & Up to 3 Days \\
\hline Cocaine & $1-3$ Days \\
\hline Heroin/Morphine & $1-3$ Days \\
\hline Marijuana - Chronic & $30-70$ Days \\
\hline Marijuana - Occasional & $1-3$ Days \\
\hline Methadone & $2-4$ Days, maybe longer (150 hours) \\
\hline PCP-Chronic & Up to 30 Days \\
\hline PCP-Occasional & $2-7$ Days \\
\hline
\end{tabular}

Table 2. Duration for a positive screen 
Metabolites also play an important role in urine drug testing. The recent use of genetic testing plays an important role in metabolite assessment. The importance of not only identifying the current drug in testing, but its metabolite, is now realized as an impact item of adherence monitoring. Transformation has occurred in healthcare that is just now being more defined in clinical personalized care. Previously the pathology, physiology, as well as chemistry have helped us understand disease. Today, the complexity of metabolic progression of clinical drug therapy can require a suitable drug that can be individualized. With the model of genomics and personalized care model, we can now follow the best course of care with specific agent selection. If an individual's hepatic metabolism does not support a 2D6 pathway, another agent might be more desirable, utilizing another p450 enzyme pathway. The concept of pseudoaddiction has been reborn. Pseudoaddiction was introduced in the late ' 80 s, based on the flawed concept that individual reports of increased pain may occur because the patient is under dosed $[74,75]$. Now with the revelation of genetic metabolic variability, it can be demonstrated that a chosen agent may be an inferior ineffective choice. Testing may suggest that it is not that the drug is underdosed as with pseudoaddiction, but there is a poor metabolic progression to activity of the chosen agent. For example, Hydrocodone is metabolized to normorphine, norhydrocodone, hydrocodol, Hydromorphone, and hydromorphol. Oxycodone is metabolized to noroxycodone, Oxymorphone, oxycodols, and oxides. Some of these metabolites are clinically active and potent, such as Hydromorphone in the case of hydrocodone. If the metabolic pathway does not exist to metabolize hydrocodone to its metabolite, such as a weak 2D6 response, the efficacy of that drug will be significantly diminished. The rate of drug metabolism may also be identified. Poor metabolizers to rapid metabolizers of a drug might affect the chosen agent and its clinical activity. Over the next few years genetics will help us tailor courses of therapy that are individualized, and help us improve patient care.

Urine drug screening and adherence monitoring is necessary to manage controlled substance therapy, and diagnose misuse, abuse, and diversion. We test patients to monitor adherence, support patient advocacy, uncover diversion, and addiction. We choose who to test as a process of adherence monitoring, coupled with informed consent. Patients tend to declare themselves during the course of treatment. Those that are resistant to certain drug or treatment profiles, push specific drug requests. Any patient with aberrant behavior, or in recovery, would be a high risk individual requiring enhanced monitoring. These tests are indicated when the physician detects a clinical indication to do so to support decision making. Often, the clinician will utilize a point of care sample, but confirmation usually follows if there is a red flag question or unclear detection of a drug. Poorly identified drugs in point of care include Methadone, Fentanyl, Oxycodone, and Tapentadol. Also GHB, anabolic steroids, designer drugs, inhalants, and hallucinogens are difficult to detect. Point of care tests are based on competitive antibodies and the drug saturates the antibody. Point of care is desirable due to the rapid turnaround time, cost, and portability, but often requires a qualitative assay. Gas chromatography liquid and mass spectrometry (GC-MS) is a common form of confirmation, but is expensive and can take a number of days. Some point of care detection sensitivities are very accurate, such as cocaine, with a primary metabolite benzoylecgonine. There is low cross reactivity with other substances, and is considered very reliable at point of care. Less so are nonspecific opioids, as well as synthetic opioids. When assessing a urine test, positive results require close analysis. 
There are many cross reactants, and positive results do not always mean an illicit substance has been ingested. For example, a morphine positive urine drug screen may also result from a metabolite of codeine, which is morphine. The reverse is not true. Also seen is the possibility of positive THC, when the patient has a prescription for Marinol. To ensure the validity of a specimen, which can be tampered by dilution and adulterants, adding verification with creatinine, $\mathrm{pH}$ and temperature are applied. High volume ingestion of water, such as two quarts, might produce a negative result with the cutoff level being diluted to a negative result. Even the internet offers tools to pass a drug test. Most are adulterants and oxidants.

\begin{tabular}{|c|c|c|c|c|}
\hline Drug & $\begin{array}{c}\text { Screening cut-off } \\
\text { concentrations } \mathrm{ng} / \mathrm{mL} \\
\text { urine }\end{array}$ & $\begin{array}{l}\text { Confirmation cut-off } \\
\text { concentrations } \mathrm{ng} / \mathrm{mL}\end{array}$ & Urine detection time & $\begin{array}{c}\text { Immunoassay (I) } \\
\text { Chromatography (C) }\end{array}$ \\
\hline Hydrocodone & 300 & 50 & $1-2$ days & $I \& C$ \\
\hline Oxycodone & 100 & 50 & $1-3$ days & $I \& C$ \\
\hline Morphine & 300 & 50 & $3-4$ days & $I \& C$ \\
\hline Methadone & 300 & 100 & $5-10$ days & $I \& C$ \\
\hline Hydromorphone & 300 & 100 & $1-2$ days & $I \& C$ \\
\hline Meperidine & 300 & 100 & $1-2$ days & $I \& C$ \\
\hline Codeine & 300 & 50 & $1-3$ days & I \& C \\
\hline Benzodiazepines & 200 & $20-50$ & Up to 30 days & I \\
\hline Barbiturates & 200 & 100 & $2-10$ days & $I \& C$ \\
\hline Marijuana & 50 & 15 & $\begin{array}{c}1 \text { - } 3 \text { days for casual use; } \\
\text { up to } 11 \text { weeks for } \\
\text { chronic use }\end{array}$ & $I \& C$ \\
\hline Cocaine & 300 & 50 & $1-3$ days & $I \& C$ \\
\hline Amphetamine & 1,000 & 100 & $2-4$ days & $I \& C$ \\
\hline Methamphetamine & 1,000 & 100 & $2-4$ days & $I \& C$ \\
\hline Heroin* & 10 & 25 & $1-3$ days & $I \& C$ \\
\hline Phencyclidine & 25 & 10 & $2-8$ days & $I \& C$ \\
\hline
\end{tabular}

*6-MAM, the specific metabolite is detected only for 6 hours.

Table 3. Urine drug testing: Typical screening and confirmation cut-off concentrations and detection times for drugs of abuse.

Adherence monitoring with urine testing is just one technique. Pill counts also reveal compliance. Depending on the personality of the patient, motivating features of their personality, and their apparent risk - mild, moderate, or high risk - different delivery systems might even be considered. The common and erroneous belief that a patch system is a significant improvement 
in safety is not borne out in the reality of pain care. These patches can be utilized nefariously, and have street value. It is recommended that spent patches associate with an accountability system, such as placing them in an envelope, or on a piece of paper with each patch dated, and returned to the clinic for inspection. In the case of Fentanyl, there is significant Fentanyl left in the patch after three days. Patients who say that their patch does not work after "two days" might be given more patches, with the increased potential for diversion. If diversion is not suspected or borne out when a properly dosed drug is ineffective, the argument for genetic testing could be made. Poor or rapid metabolism is possible, and alters the effectiveness of the chosen agent. Those at high risk, such as those that are on Medicaid or disabled, have a history of substance abuse, bipolar, borderline personality, chaotic lifestyle, and alcoholism, and those that exaggerate symptom response, require significant adherence monitoring. Drug testing may be more frequent than two times a year, as are pill counts and other adherence monitoring techniques. Plans must be in place with written agreements that include informed consent and therapeutic boundaries understood by the patient, family members, and relevant individuals, such as those with power of attorney. There are some patients that controlled substances just are not safe enough to give, or will be misused, in which the clinical course of care begs another form of treatment such as interventional medicine, manual medicine, or other pharmacologic manipulations. Those that have deviations from the patient care agreement, adulterance of the urine, misuse, abuse, or divert, should be introduced to a pathway in their best interest. Simply discharging the patient is unacceptable. Offers to afford the patient care in another arena are considered good medical care, and referrals to psychiatry, addiction medicine, methadone clinics, and other community services are strongly urged. The process of abandonment cannot be ignored. The reality of those that use controlled substances is that most make mistakes. This does not mean that they are bad people, or do not have a legitimate medical illness that can be treated by other means.

\section{PDMP}

The prescription database management systems or programs (PDMP) that are seen in nearly all 50 states identify the origin of the prescription, the physician, and the details of the prescription such as number of pills, refills, and date. Utilizing this information, the practitioner will then determine if the patient is utilizing medication properly, if violation of patient care agreement is evident, and ensure that compliance is in place.

\subsection{Communication}

Pain care in modern medicine is an expectation that has even been assigned its own vital sign. Unlike a number of years ago, care providers are becoming more enlightened regarding the necessity and societal need for pathways of relief in those that are impaired by pain. Methods and techniques of pain treatment are as varied as the providers that care for these individuals. A full spectrum of care is available today, from manual therapy to interventional medicine, and pharmacologic strategies have many choices. Occasionally the clinician is challenged to provide adequate care, but lacks the availability of the proper therapeutic option. Chronic pain 
care by its very nature will be treated by multiple specialties, each offering its own solution. The Code of Ethics published in the American Medical Association 1847 "from the age of Hippocrates to the present time, the annals of every civilized people contain abundant evidence of the devotedness of medical men to the relief of their fellow creatures from pain and disease" [76]. By the very nature of pain and its associated diagnosis, cross specialty cooperation is necessary to obtain the best outcome. It is therefore, the duty of a care provider to offer pain care and relieve suffering. Edwards, in Pain and the Ethics of Pain Management 1984 stated "there is a duty to do all that can be done within the limits of current medical knowledge and available resources to relieve all the pain and suffering which can be alleviated" [77]. Herein lies the problem. Not all chronic pain disease states can be clearly defined, unlike other medical disease states. Pain is really the reflection of an individual's own subjective interpretation that has a number of biopsychosocial influences.

Chronic pain care is also constrained by the financial and medical/legal environment. From a regulatory perspective, the pain care provider may find road blocks to address an individual's pain. Fear of reprisal or a negative peer opinion will often lead to under treatment of pain. Other providers don't find an interest in treating pain because of the vagarity of an individual diagnosis and lack of diagnostic tools available to assess the patient that has pain. Pain is one of the most common complaints in a physician's office, and is often the lowest point of focus. Pain is more than a symptom; it is also reflective of a disease state or illness, and is rarely a singular disease entity. Comorbidity should be expected. This further complicates the treatment pathway and promotes polypharmacy. The patient develops a "personality of pain" responsible for inflicting emotional, and neuropsychiatric impairment. This psychological decay further leads to decline in function. The complexity of the pain diagnosis can change the identity of an individual that diminishes the feeling of wellness from every aspect of an individual's life. Situational depression and anxiety are deleterious problems in the patient suffering from pain, and are often a comorbidity. Magnified by the lack of cohesion in pain care, these different facets of pain diagnosis often go untreated, diminishing the potential effectiveness of a prescribed treatment course. It is not that a certain medication pathway, or interventions "don't work", it is more likely that the individual patient is not treated as a whole. This fragmented care is costly to the patient and society.

Over the past ten years the prevalence of chronic pain has remained a consistent challenge for providers and patients. The advances in treating pain primarily revolve around pharmacologic management, interventional tools, and musculoskeletal therapy. The realities of our evolving healthcare delivery systems may continue to limit access to this already under treated population. Now considered a fifth pathway, pain itself will be unlikely to support a priority position in the healthcare hierarchy. With innovative payment programs such as ACOs, and the remnants of managed care, priority will be given to chronic life-threatening disease states, and then followed by those with progressive disabling afflictions. Chronic pain, which is many times disabling, is not a life-threatening entity. The pain provider will be challenged to render effective care, increasing function and quality of life, and minimizing risk in the new order. With rising healthcare costs opioid use has increased. Escalating opioid use has a direct relationship with adverse consequence. Considered inexpensive, opioid therapy is actually 
quite costly. The potential for abuse events and long-term use may be significantly higher than adjunctive or interventional options.

Clinical Vignette. A new patient complains of low back pain. He was referred for medication management. Payer source is Medicaid, he does not work, and the MRI reveals modest degenerative changes. He is a smoker, and recently divorced. The exam reveals nonphysiologic findings and otherwise unremarkable.

At initial visit, an intake questionnaire suggested possible use of a controlled substance that was supplied by a family member, and a urine drug sample is obtained. Within the sample, nonspecific opioid at point of care was found, and was positive for THC.

The patient is requesting a pain prescription, and is persistent as to the need to obtain "Oxys" so he can go look for a job. He has been on these before and that is the only thing that works, specifically defining the medication needed that doesn't have Acetaminophen, which upsets his stomach.

A number of issues arise with this vignette, specifically the lack of a clear pain diagnosis. A diagnosis is a necessary component of the controlled substance management plan, and necessary to the medical record. Low back pain is a common complaint, but it is just that, a complaint or a symptom, not a diagnosis. The exam rendered very few clinically relevant findings and the supportive imaging was not remarkable. The patient is specific on the type of medication wanted, in its pure form, and has a chaotic home life. The original history did not bring forward the use of hydrocodone, which was extracted after the point of care testing found unexpected opioids, and THC, illegal substances evident. This is a red flag encounter. A number of inconsistencies and elements of inappropriate seeking behaviors are evident. This coupled with the lack of clear diagnosis, the willingness to take someone else's medication, is counterproductive to establishing a firm patient/physician relationship built on trust. Even the fact that the individual is on a government assistance program increases the risk of misuse.

The clinical scenario would suggest to many providers that this patient needs to be discharged from the clinical environment. This might be a common approach, but it is not the best approach. An individual that has red flags is an individual that requires adherence monitoring and advanced care. With the epidemic of opioid prescription drug deaths, it is this type of individual that does need an intervention. Simply dismissing this individual places the patient and community at risk. This individual will doctor shop, going from practice to practice until they are satisfied, and likely return to that provider with increased requests. The chaotic lifestyle will usually evolve into expectations of a prescription when pills are lost or stolen.

The use of controlled substances for recreational purposes was not realized to the full extent until the era of the late '90s. Prior to 1996, DAWN and ARCOS data did not reveal a particular trend of abuse, misuse, or diversion. That same period of time medical use was increasing rapidly, but there were no particularly revealing trends that divulged the urgent need for increased scrutiny of these agents. Some believe that the increased use of opioids is enhanced realization that chronic pain is undertreated. Recently, however, the trend is more alarming. Even though there is a slight reduction in opioid use overall, misuse has increased. 
As with any treatment, the risk/reward benefit is carefully considered prior to initiating therapy. In the case of this vignette, or any scenario where opioid management is considered, the conscious decision to prescribe or not prescribe is based on clinical support. The expectation is that opioids will increase function and quality of life, but that does not always seem to be the case. Despite evidence that opioids do not improve quality of life and may actually increase disability, the use of opioids and controlled substances for the subjective complaints of pain remain robust. Further underscoring this irony is that chronic opioid use lacks evidence supporting use, an abundance of evidence exists that these agents are risky and in certain patient populations, dangerous. Despite remedial efforts at educating the medical community, widespread opioid use promotes misuse, abuse, and diversion. In the case of low back pain, a physician that is pressured in the primary care office for time, and a patient's insistence on obtaining a controlled substance, it is often easy to prescribe and avoid confrontation. Our society is becoming increasingly tolerant of previously forbidden drugs. We are entering into the marijuana era, where states assess the tolerance for recreational use, and legalize the drug for sale and distribution. Patients will then perceive, as many do now, that marijuana is an innocent drug. Marijuana is, however, a drug of abuse. Impairment is a side effect of the drug, just as alcohol and benzodiazepines. Despite states opinions, marijuana is illegal at the federal level. Most providers have entered into an agreement with the Drug Enforcement Administration that they will prescribe by community standard, and will withhold prescriptions when illegal drugs are used. At the federal level, marijuana remains a schedule I drug, where no medical use is defined. Those that prescribe have a DEA certificate that is federal, not controlled by the state, which establishes a legal and ethical question between patient and provider. If a patient perceives marijuana as part of their necessary routine, is it legal and ethical for a physician to prescribe a controlled substance? This question has not been answered.

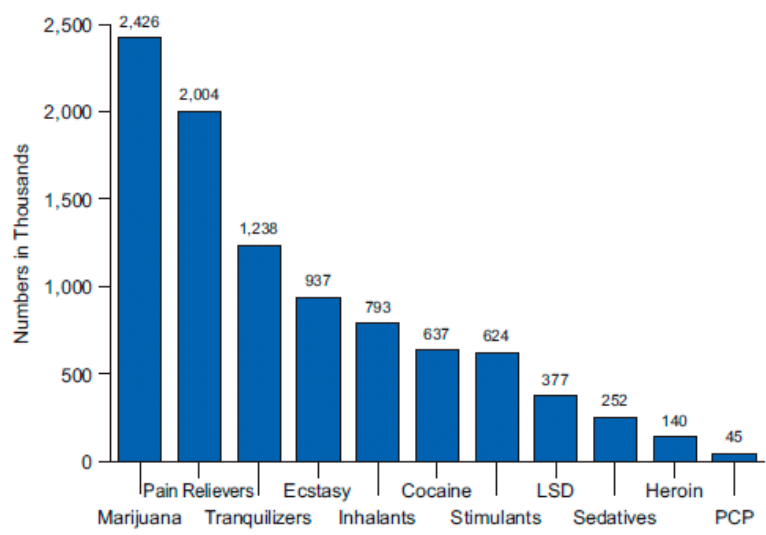

Note: The specific drug refers to the one that was used for the first time, regardless of whether it was the first drug used or not.

Again the risk/reward benefit should be considered foremost in a medical practice. The common denominator of the provider and the patient is the healing interaction in the clinical 
construct as understood by the patient and clinician equally. When one of the parties, in the case of the vignette, is outside of the expected clinical norm, care options are limited, such as opioid use. Controlled substance management is the most likely choice to be eliminated when aberrancies are noted. Many care options in chronic pain medicine are discretionary, and believe that a patient's pain is "real." Pain is subjective, with physiologic and psychologic comorbidities, and requires the provider to acknowledge the difficulties of treating those in pain. The prescribing physician and the patient enter a cooperative agreement. Each understands expectations and boundaries.

\section{Regulatory agency pressure}

Regulatory agencies such as state medical boards in the United States, the US Food and Drug Administration, as well as law enforcement agencies are under pressure to crack down on over-prescribing and "pill mills". The Physicians for Responsible Opioid Prescribing (PROP) have recommended changes in the labeling indication for opioids [78]. They have recommended limiting the labeling indication for opioids to limit the duration of opioid therapy to 90 days and limiting the dose to $100 \mathrm{mg}$ /day of morphine equivalents. This expert group also recommends limiting opioid to severe pain rather than moderate pain. These recommendations do not apply to end of life care. The consequences of labeling changes such as these would make chronic opioid therapy an "off-label" use and many physicians would be reluctant to continue prescribing chronic opioid therapy that is considered "off label". If the FDA adopts the recommendation of the petition, signed by experts, it would create a new and unfavorable environment for practitioners and patients. Access to pain care would be reduced.

\subsection{Clinical situations as an Alternative to Chronic Opioid Therapy}

Clinical Vignette. A rancher takes three hydrocodone per day for osteoarthritis of the knees for years. His orthopedic surgeon wants to wait a few more years before replacing his knees. The patient does not drink alcohol or use other controlled substances, and he continues to work cattle on his ranch. He breaks his own horses.

Some patients do well with opioids, and do not require escalating doses. Without significant dose escalation, they retain a high level of function. In this particular individual, the diagnosis is clear, there have been no discernable side effects, and he is able to continue with his activities of daily living, enjoying a high level of function despite his arthritis.

An elderly patient with spinal stenosis has a history of gastrointestinal bleeding felt to be triggered by anti-inflammatory agents, and reports no significant relief with non-narcotic medication alternatives, including maximum dose of acetaminophen. She has been intolerant of tricyclic antidepressants and gabapentinoids. She is unable to afford non generic therapy. Hydrocodone is intolerably constipating, but she is able to function with Tramadol, and is being treated in an interdisciplinary environment.

This particular patient is an individual that has failed non-narcotic options, but has a spine that may be treated with an interventional approach. She may be a candidate for caudal lysis 
of adhesions, or the recently introduced minimally invasive lumbar decompression (MILD) procedure, or both before proceeding with further spinal surgery. Certain patient populations are felt to be poor candidates for opioid therapy or unable to tolerate the side effects. Patients with chaotic lifestyles, post-traumatic stress disorder, and certain types of anxiety and depression lead to misuse and potential abuse. Habituation and lack of efficacy are significant problems with opioids. Opioids have been reported to interfere with the treatment of anxiety, and may lead to an actual decline in quality of life, and promote pain and disability. Other groups with obesity, multiple symptom etiologies, and vague pain complaints that do not have a clear substantiated diagnosis are also less attractive candidates for opioid therapy. Risk items might include older age, female, antisocial personality, government disability, severe disability initial evaluation, not working at discharge, and previous history of misuse, abuse, and DWI. As might be expected, the longer a person is out of work the less likely they are to return. Opioids prescribed for longer than 7 days have been reported a risk factor for long-term disability in workers with acute back pain. The 52 week study showed no major outcome differences between patients treated with stable opioid regimen versus escalating opioid dose regimen. Higher doses are not always associated with additional benefits, and the potential of introducing opioid-induced hyperalgesia is another item of concern when utilizing opioids in chronic therapy. This 52 week study had a dropout rate of $27 \%$ due to misuse, which is very consistent with a number of other studies that reveal opioids are misused by $20-25 \%$ in various patient populations. A retrospective study found no correlation between opioid dose and pain severity in patients with chronic pain who took opioids for an average of 704 days. These patients were treated with higher doses in response to elevated pain complaints, and it was observed that patients on lower doses reported less pain. Conclusions are difficult to discern between the potential for hyperalgesia, versus dosing resistance.

A unique population that is emerging as a significant opioid use category is pregnancy. Of the 1.1 million pregnant women enrolled in Medicaid, 23\% filled an opioid prescription in 2007. This is up almost $19 \%$ from 2000, according to a recent study published in Obstetrics and Gynecology [79]. It is estimated that 1 in 5 women use opioids during pregnancy. Another study revealed 500,000 privately insured women found $14 \%$ were dispensed opioid pain killers at least once during their pregnancy. The rate of opioid prescriptions was the highest in the south and the lowest in the northwest. In the study, of the women enrolled in Medicaid, 41.6\% of pregnant women in Utah were prescribed opioids, and Oregon had the lowest at $9.5 \%$. This regional discrepancy does not reflect differences in pain states, but the willingness of the provider to prescribe opioids. Opioids do not have a sufficient number of studies to demonstrate safety in this population. Increasing use of opioids during pregnancy may lead to neonatal abstinence syndrome. It is likely that society expects some type of medication be utilized for pain relief when acetaminophen is not effective. Possibly explaining the increased use is that opioids are one of the few choices other than medication for relief during pregnancy.

Diversion of prescribed opioids remains a rising problem with the young people. Among persons aged 12 older who used pain relievers nonmedically, 55\% report they received the drug for free from a friend or a relative, while another $11 \%$ bought the drug from a friend or 
a relative. 7 million, $2.7 \%$ of the population, persons aged 12 or older used prescription-type drugs nonmedically in the past month.

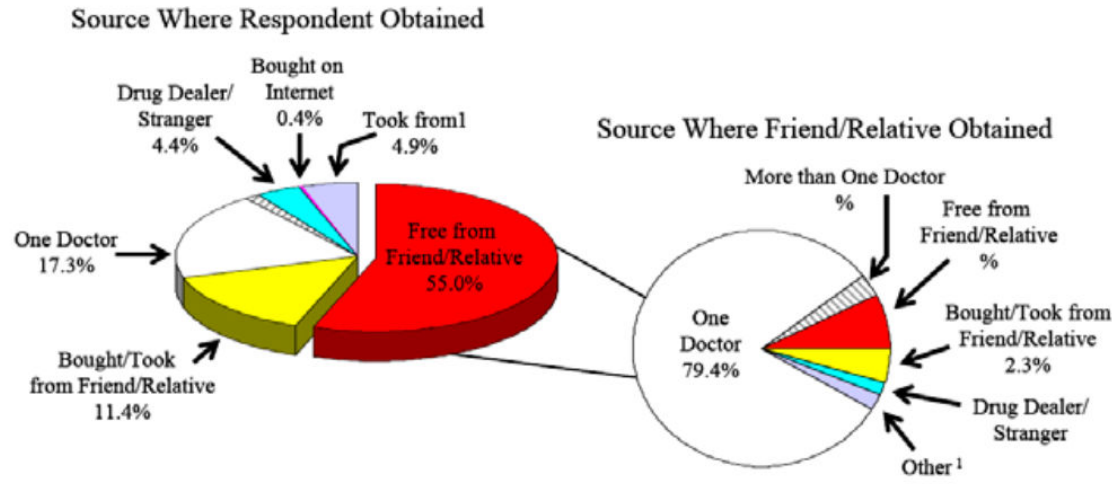

5 million of these used pain relievers. There is no validated risk assessment tool that exists to clearly identify and prevent diversion. Chronic pain may be the complaint, but in one study almost $40 \%$ of those addicted to prescription medications eventually switched to heroin $[79,80]$.

\section{Overdoses}

Overdoses occur, and are a feared complication of controlled substance management. Overdoses on opioids alone are relatively uncommon. Usually overdoses occur with polypharmacy, other offending agents usually being benzodiazepines, or barbiturates. Barbiturates, mixed with alcohol, is a combination with opioids that is extremely hazardous. Although opioids are the most common drug class associated with overdose, the combination of opioids with benzodiazepines and other psychotropic drugs are associated in up to $10 \%$ of overdoses. A study in 2006 of West Virginia overdoses was found to be associated with nonmedical use and diversion of opioids, only $44 \%$ of victims had been prescribed the found drug.

\section{Informed consent}

Informed consent is not an optional endeavor in the clinical setting. It is a process, in which there is a communication, established clearly, with no barriers to communication between the physician and the patient. Many times the patient is not the one that would be the necessary recipient of informed consent, such as in the event of a patient rendered insensible, under the context of a court order, or power of attorney. Informed consent is an interrelationship between the patient, physician and society. It is a process that involves many steps, and the physician is ultimately held responsible for breakdown in informed consent. 
The process of informed consent is both a legal and clinical action and is a process of protecting the communication lines, and avoids misrepresentation of understanding, and ultimately communication failure. It assumes the physician is an educator to the patient, family, and medical community, and requires that all aware are in acceptance, and aware of potential risks and benefits to a particular treatment or therapy. Informed consent is a necessary element of controlled substance management. Poor communication resulting in altered expectation of the family and patient is a leading factor in the generation of lawsuits. Informed consent reduces this risk and assumes that standard of care between a reasonable prudent physician, nurse, physician's assistant, nurse practitioner, or other provider exists, that has similar training. Under similar circumstances these providers would react to medical issues that establish the standard. A physician has a duty to disclose to his patient the risk of injuries that might result from proposed course of treatment. The American Medical Association guidelines define the physician should

- disclose the patient diagnosis if known

- the nature of proposed treatment or procedure

- the risks and benefits of proposed treatment or procedure

- alternatives

- the risks and benefits of alternative treatment

- the risks and benefits of not receiving or undergoing the treatment.

These guidelines are not requirements, but this list effectively establishes a standard of care by which a physician's disclosures are measured. In general, a physician does not need to advise a patient of every conceivable risk but only the substantial risks must be disclosed. That might be what a physician would reasonably know to be a part of the treatment course, and allowing the patient to decide whether they would want to consider moving forward. Informed consent may be verbal, but documentation establishes a better pathway to defend a dispute. Care must be taken that the individual who is providing informed consent is adequately trained to understand the importance of this task. The patient should have a clear understanding of the implications of informed consent, and ample time to ask questions, and engage in dialogue that addresses the patient's concerns.

Many guidelines now recommend obtaining separate and specific informed consent for opioid treatment. Warning patients of addiction risks as well as overdose and diversion are important. The Federation of State Medical Board rules state:

"Informed consent documents typically address:

- The potential risks and anticipated benefits of chronic opioid therapy.

- Potential side effects (both short-and long-term) of the medication, such as constipation and cognitive impairment.

- The likelihood that tolerance to and physical dependence on the medication will develop.

- The risk of drug interactions and over-sedation. 
- The risk of impaired motor skills (affecting driving and other tasks).

- The risk of opioid misuse, dependence, addiction, and overdose.

- The limited evidence as to the benefit of long-term opioid therapy.

- The physician's prescribing policies and expectations, including the number and frequency of prescription refills, as well as the physician's policy on early refills and replacement of lost or stolen medications.

- Specific reasons for which drug therapy may be changed or discontinued (including violation of the policies and agreements spelled out in the treatment agreement)."

\section{Opioid agreements}

An opioid agreement is sometimes called "a contract." The opioid contract implies a legal component, so better terminology is an "agreement" between the prescriber and those receiving the controlled substances. The opioid agreement, or controlled substance agreement, is an understanding between all parties that there will be one source of prescribed medication that is of controlled nature, and one dispensing pharmacy. There can be some practical adjustments, but the reality is that it is necessary to have this document in place so there is no barrier to communication.

Opioid agreements encourage patients to avoid dose escalations, multiple prescribers and pharmacies, and inform patients of opioid tapering and discontinuation of opioid may occur if necessary.

The Federation of State Medical Board rules state:

"Treatment agreements outline the joint responsibilities of physician and patient and are indicated for opioid or other abusable medications. They typically discuss:

- The goals of treatment, in terms of pain management, restoration of function, and safety.

- The patient's responsibility for safe medication use (e.g., by not using more medication than prescribed or using the opioid in combination with alcohol or other substances; storing medications in a secure location; and safe disposal of any unused medication).

- The patient's responsibility to obtain his or her prescribed opioids from only one physician or practice.

- The patient's agreement to periodic drug testing (as of blood, urine, hair, or saliva).

- The physician's responsibility to be available or to have a covering physician available to care for unforeseen problems and to prescribe scheduled refills." 


\subsection{Sample Opioid Agreement}

The following agreement relates to my use of controlled substances including, but not limited to "narcotics/opioids," to treat chronic pain. I will be provided with the prescriptions only if I understand and agree to the following:

1. I understand that, depending on the drug and dose, I can become physically dependent on the medication and can develop withdrawal symptoms if the medication is stopped suddenly or the dose reduced rapidly. Although the risk is small there is a chance of developing an addiction to controlled substances if I am placed on them to help control my pain.

2. Controlled substances can cause sedation, confusion, or other changes in mental state and thinking abilities. I understand that the decision to drive while I am taking controlled substances is my own decision, and I agree not to be involved in any activity that may be dangerous to me or someone else such as driving or operating any dangerous equipment, working in unprotected heights or being responsible for another individual who is unable to care for himself or herself if I am in any way sedated, feel drowsy or am not thinking clearly.

3. I will not use any illegal substances including, but not limited to, marijuana and cocaine. I will not drive while impaired with alcohol or other substances.

4. The Receiving Controlled Substance Policy regarding the dispensing of controlled substances requires that I be seen regularly and I agree to make and keep my appointments. I will advise my doctor of all other medicines and treatments that I am receiving.

5. If the medication requires adjustment, an appointment must be made to see the doctor. No adjustments will be made over the telephone. My careful planning is required. I understand that medication refills and adjustments are done during office appointments. I must stay with the prescribed dosing so that I do not run out of medication early. I understand that the Refill Policy is NOT to prescribe early. I agree that I will use my medication exactly as prescribed and that if I run out early, I may go without medication until the next prescription is due, possibly resulting in withdrawal symptoms.

6. I understand that the prescriptions are my responsibility once they are placed in my hand and that if anything happens to my prescription (lost, stolen, or accidentally destroyed), I may NOT receive a replacement from my physician. I am expected to file a police report if my medication is stolen. I will be prepared to bring in a copy at my next REGULARLY scheduled visit.

7. My physician will prescribe whatever medication he/she is comfortable with and thinks is best; he/she is not under any obligation to prescribe any specific medications.

8. I am aware of the possible risks and benefits of other types of treatments that do not involve the use of opioids. The other treatments discussed include: injections, therapy, and surgery (if indicated).

9. I agree to come to (Insert Facility Name) with my medication on the same day that I am called and submit to a pill count, and/or urine or blood screening to detect illegal substances or confirm proper use of prescribed medication. The call to come to (Insert Facility Name) can be made either randomly, or if a concern arises. I may be required to bring my unused medication routinely to each office visit. If I do not have insurance or my insurance denies testing, I will be responsible for the cost of the test.

10. I give permission to (Insert Facility Name) to call any pharmacy or another health care provider at any time, without me being informed, to discuss my past or present use of controlled or illegal substances.

11. I will not use my pain medication in higher than prescribed amounts for new problems that arise (toothache, surgery, etc.) unless authorized to do so by (Insert Facility Name). I will inform my other doctor(s) of my use of 
medication for chronic pain, and I will inform (Insert Facility Name) if another physician prescribes controlled substances for the acute problem and I will not mix the medications unless advised to do so by a medical professional either (Insert Facility Name) or the prescribing provider of the acute medication. I understand this is only in acute situations and documentation of the situation must be provided to (Insert Facility Name). My doctor at (Insert Facility Name) is my primary doctor with regard to my pain medications. If there is a medical emergency (e.g. broken leg, surgery requiring post-op pain medication, dental procedures, etc.), another doctor may prescribe pain medication to me, but I will advise the prescribing doctor of my care at (Insert Facility Name) including my binding contract, and authorize the doctor to disclose information to (Insert Facility Name), and I will also notify my doctor at (Insert Facility Name) of the medication and the dosage as soon as the emergency occurs (if after hours, it's my responsibility to call first thing the NEXT business day). It will also be up to my provider at (Insert Facility Name) to determine if it was a true emergency requiring additional medication, if not my contract from this facility may be voided.

12. (Females only) Because of the risks of certain medications to unborn children, I will inform all physicians, obstetrician/gynecologist and (Insert Facility Name) immediately if I become pregnant or decide to try to become pregnant. I am aware that should I carry a baby to delivery while taking these medicines; the baby will be physically dependent upon opioids. I am aware the use of opioids is not generally associated with risk of birth defects. However, birth defects can occur whether or not the mother is on medicines and there is always the possibility that my child will have a birth defect while I am taking an opioid. I am also aware that opioids may alter my hormones as well.

13. (Males only) I am aware that chronic opioid use has been associated with low testosterone levels in males. This may affect my mood, stamina, sexual desire and physical and sexual performance. I understand that my doctor may check my blood to see if my testosterone level is normal.

14.My physician can wean me off of controlled substances at any time if he/she feels that it is in my best interest. (Insert Facility Name) will follow relevant laws when weaning me off of my medication. The weaning process can result in withdrawal symptoms. If I am weaned off, (Insert Facility Name) staff may inform my other health care providers as to the reasons for the weaning. (Insert Facility Name) may send me to a detoxification facility if indicated. I understand that (Insert Facility Name) will not be responsible for weaning me off of Methadone if I present with that in my system.

15. Abstinence Syndrome (Withdrawal Syndrome): Stopping my opioid, anti-seizure or antidepressant medication abruptly may result in withdrawal symptoms (flu-like symptoms, GI distress, diarrhea, sweating, heart palpitations, and rarely seizures or death). I should wean from my medications rather than stopping them abruptly. It is my responsibility to keep up with the amount of medication I have. I will make my appointments accordingly, before I run out.

16.I understand that in general I may be weaned off of my medication or my drug therapy may be terminated at the discretion of my physician if any of the following occur:

a)It is the opinion of my physician that controlled substances are not very effective for my pain and/or my functional activity is not improved.

b)I misuse the medication.

c)I develop rapid tolerance or loss of effect from this treatment.

d)I develop side effects that are significant and detrimental to me.

e)I obtain controlled substances from sources other than my provider at (Insert Facility Name) without informing him or her.

f)Pill counts or test results indicate the improper use of the prescribed medication or the use of other drugs, and/or I fail to submit to such counts/tests on the day that I am called. 
g)I am arrested and/or convicted for a controlled or illicit drug violation including drunk driving.

h)Any violation of this agreement.

17. I further understand that my drug therapy will be terminated or detoxification in a controlled environment will be required if I give away, sell, distribute and/or transport with the intent to sell or dispense my medication.

18.I choose to use Pharmacy, located at

for all of my pain medication prescriptions. I will not fill partial

prescriptions if my pharmacy does not stock the full quantity of medication. If I change my pharmacy for any reason, I agree to notify my pain physician.

I have read the above Agreement, understand the Agreement, have had all my questions concerning this Agreement answered to my satisfaction, and I agree to abide by the terms of this Agreement if I am placed on controlled substances (including, but not limited to narcotic analgesics). I have received a copy of the Agreement. By signing this form voluntarily, I give my consent for the treatment of my pain with narcotic/opioid pain medicines.

\begin{tabular}{c}
\hline Patient \\
\hline Physician \\
\hline Witness
\end{tabular}

\begin{tabular}{c}
\hline Date \\
\hline Date \\
Date
\end{tabular}

\section{Screening questionnaires}

The screening questionnaires available for controlled substances are often referred to as opioid risk tools, or ORTs. A number of these exist online, and can be referenced for use. Some are validated and some are not, but they are typically used to identify the risk of addiction, abuse, depression, anxiety, potential for diversion, and overdose among others. Also, comorbid diseases such as depression may be screened for. The usefulness of these tools is not known. They do not identify illegal use, abuse, or diversion.

\section{Opioids and delivery systems}

A number of synthetic and semi-synthetic opioids are utilized to control pain. The patch delivery system, uniquely associated with Fentanyl, has now been adopted with buprenorphine. Newer molecules such as Tapentadol utilize ascending and descending central nervous system pathways for pain control. Hydrocodone and Oxycodone are among the most commonly used opioids in the United States, and morphine is still considered the gold standard, of which the potency and efficacy of the opioids are measured. Methadone is a synthetic opioid that is inexpensive and long-acting. Methadone has been used for years to prevent patients in recovery from relapsing and using heroin and other street-borne opioids. Methadone clinics typically require patients to come to the clinic daily to receive a daily dose which prevents 
overdose. Methadone is associated with its own unique problems including cardiac arrhythmias, and the interaction that it has with many drugs through hepatic metabolic pathways. This makes the half-life of Methadone variable, introducing the drugs unpredictability to the pain care community. Methadone is considered a drug of enhanced risk in this regard. If used at all, Methadone doses should be initiated at low levels and monitored closely.

\section{Fentanyl}

Fentanyl is an opioid of choice in patients with renal failure or allergy to morphine. Transdermal patch preparations have been associated with less constipation compared to oral opioids, and the delivery system assists in adherence if pills are problematic. However, the steady state of fentanyl may not occur until 12 hours after a dose change so it is not a good sole agent in acute pain settings where dose adjustments need to be made frequently. Even small doses have been associated with respiratory depression and death. Recently, Fentanyl has gained street popularity by mixing with heroin.

Transdermal fentanyl is now available in a lower dose of 12 micrograms per hour. Fentanyl oralets are available in 100 microgram preparations and fentanyl oral film is also available for oral mucosal administration. The buccal absorption is utilized in cancer pain therapy, and onset is rapid.

\subsection{Opioid conversion}

Patients may need opioid conversion to another opioid for a number of reasons. Sometimes cost is a factor, or rotation to another agent for metabolic reasons such as tolerance and metabolic inefficiency. Multiple opioid conversion charts exist and are of limited value. The emergence of genetic testing has demonstrated that unique patient characteristics do influence the effectiveness of opioids. Incomplete cross-tolerance may exist between different opioids and care should be exercised when converting high doses of opioids. Particular care is exercised with methadone and transdermal patches of fentanyl since a steady state is not reached quickly with these drugs. Dose escalations should be made after several days of treatment rather than changed on a daily basis. Patients are likely to retain previous prescriptions of opioids and may use old prescriptions of long acting opioid to supplement new prescriptions. Some patients may need hospitalization for opioid management and drug holidays, or formally detoxed.

\subsection{Other drugs}

Ketamine, buprenorphine, butorphanol and other classes of drugs may also be abused or misused along with opioid agonists. Many of these drugs are not detected by routine drug screening, and physicians should welcome information from the patients' family members or friends about the patient's drug and alcohol use. 


\section{Clinical vignette}

A patient with mesothelioma repeatedly escalated their analgesic and called for early refills. The doses exceeded recommended doses and the patient was repeatedly counseled. The patient would not comply and the medication was discontinued. The medication was ketorolac. The behavior was indistinguishable from opioid addiction. This patient eventually died and was managed with other treatments but none were as effective as the intravenous NSAID administered by the patient via a port.

Lesson learned-pseudo-addiction is a real condition and some patients are not able to cope with pain and comply with treatment recommendations. NSAID and acetaminophen abuse are significant problems.

\subsection{Intrathecal opioid}

Intrathecal opioid infusions have been used to limit oral opioid consumption and control patients who self-escalate doses of opioids. There is little data to support the notion that spinal opioids prevent addiction; however, in a randomized trial of intrathecal opioid versus oral opioid for cancer pain management, patients treated with intrathecal opioid had a 6 month survival rate of $52-59 \%$ compared to $32 \%$ in the oral opioid group. [81] This suggests that intrathecal opioid may have a safety benefit related to controlled dosing.

\subsection{Clinical vignette}

A patient had an outpatient trial of intrathecal morphine but did not disclose that they were seeing a psychiatrist who was prescribing benzodiazepines. The patient had a respiratory arrest the morning after the injection.

Lesson learned-intrathecal opioid injections may not have a peak effect until the next day. Patients may need to be hospitalized for trials with intrathecal opioids, especially morphine or other opioids which may have a delayed peak effect.

The Wiley catheter may be used for intrathecal opioid trials and has been associated with a lower incidence (3\% versus $10 \%$ with larger catheters) of spinal headache in obstetrical patients. [82]

Patients, who respond to a test dose of $0.5 \mathrm{mg}$ of morphine or less, tend to maintain responses to intrathecal opioid. Other factors of success include female gender, age over 65 and a diagnosis of peripheral neuropathic pain. Patients with cervical pain and visceral pain tend to require more rapid dose escalations. [83]

Patients, who respond only to higher doses during a trial, require more dose escalations, conversations to alternative opioids, including oral opioids, and the addition of additional agents such as bupivacaine. Lower daily doses of morphine, as a single agent, may be associated with less risk for granuloma formation, which has been a significant problem with long term intrathecal opioid therapy. Meperidine has been associated with pump malfunctions and should be avoided. 
Popular opioid conversion ratios of 100:10:1 for intravenous to epidural to intrathecal may vary significantly in clinical application, and conservative doses should be used to avoid overdoses. Morphine concentrations of $20 \mathrm{mg} / \mathrm{ml}$ and doses of $0.25 \mathrm{mg} /$ day are ideal.

\section{Interventional pain management as an alternative to chronic opioid therapy}

Procedural interventions to treat pain are attractive options to avoid known and unknown risks of chronic drug exposure. Frequently, interventions assist in diagnosis of the painful state and reduce the opioid load. Also, the cost of some drug therapy is substantial and comparable to procedures over time. Some patients report prolonged periods of pain improvement following interventional procedures.

An example of a useful interventional procedure is epidural lysis of adhesions after years of chronic low back and leg pain. Patients sometimes retain years of improved function and quality of life after this procedure.

\section{Interdisciplinary treatment as an alternative to chronic opioid therapy}

Interdisciplinary pain management, as an alternative to continuing chronic opioid therapy, has been offered to patients over the past year in our practice. The interdisciplinary program included 8 half day sessions over a 4 week period. Each half day session included 1 hour of cognitive behavioral therapy as a part of a structured sequence of sessions. Theories of pain, relaxation techniques, cognitive restructuring, stress management, pacing, pleasant activity scheduling, anger management, assertiveness training, sleep hygiene, and planning for flareups included in the curriculum of care. Each half day session also includes 1 hour of psychoeducational group therapy to complement the individual cognitive behavioral therapy. 1 hour of physical therapy for general conditioning, specific range of motion and strengthening is also an integral part of the program. Physician visits are scheduled during these half day sessions for medication management and limited interventional pain management.

45 patients completed the interdisciplinary treatment program and were able to reduce or eliminate opioids. At the same time, functional improvement was made across multiple measures. Figure 1 shows average pain in previous week. Patients' median pain score dropped approximately $35 \%$ after the interdisciplinary treatment.

Figure 2 shows a drop in median opioid dose from low to none. In this analysis, $1=$ =no opioid, $2=$ low opioid dose (1-40mg per day of oral morphine equivalents), $3=$ moderate opioid dose (40-100 mg per day of oral morphine equivalents), 4=high dose opioid (greater than $100 \mathrm{mg}$ per day of oral morphine equivalents). 
Self-Reported Avg Pain in Previous Week (PreTx and PostTx)

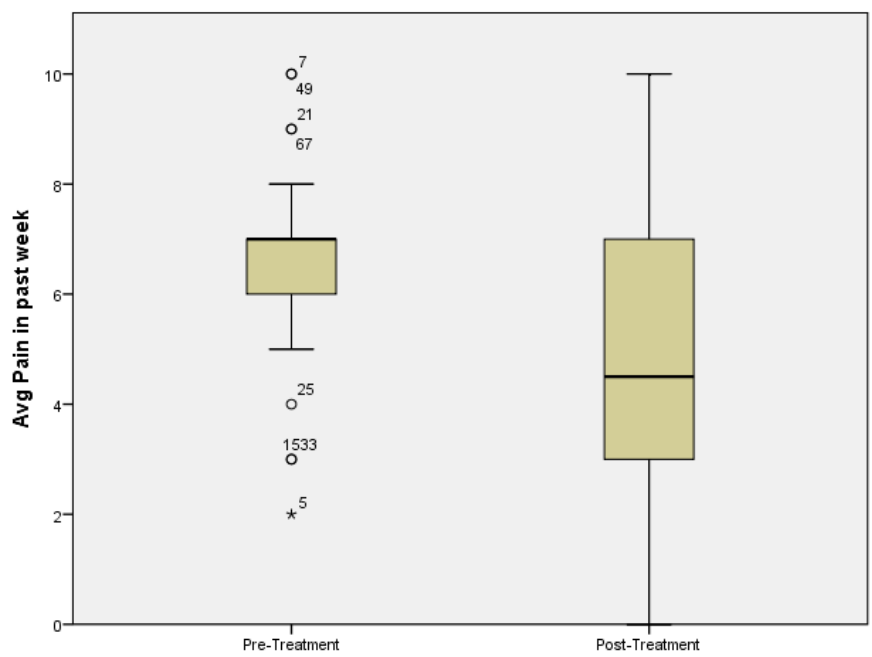

Figure 1. Visual analogue pain scores

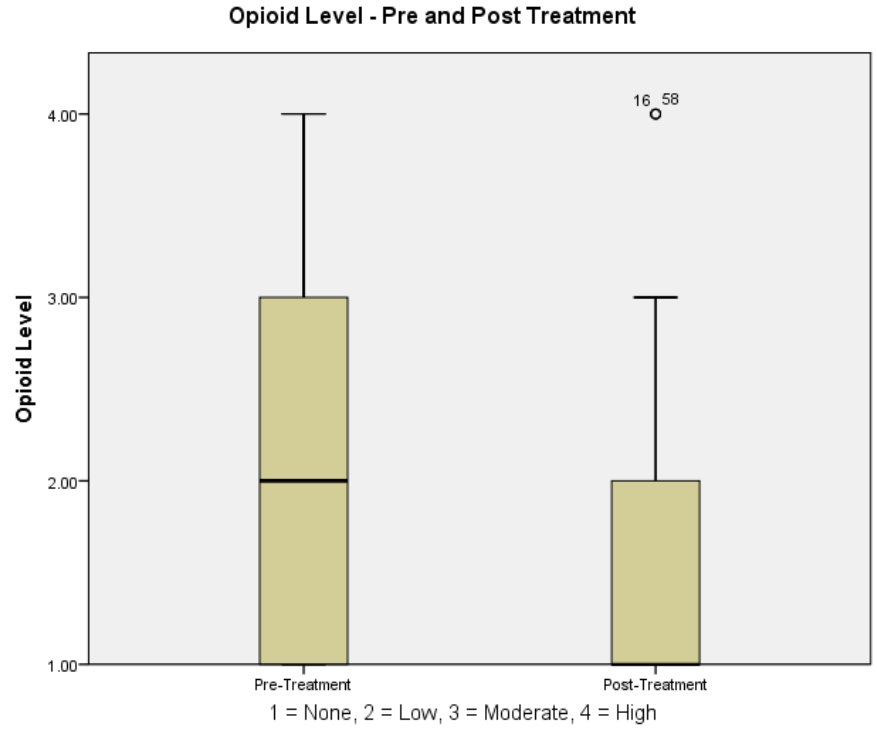

Figure 2. Opioid doses 
Figure 3 shows a reduction in pain interference after interdisciplinary treatment.

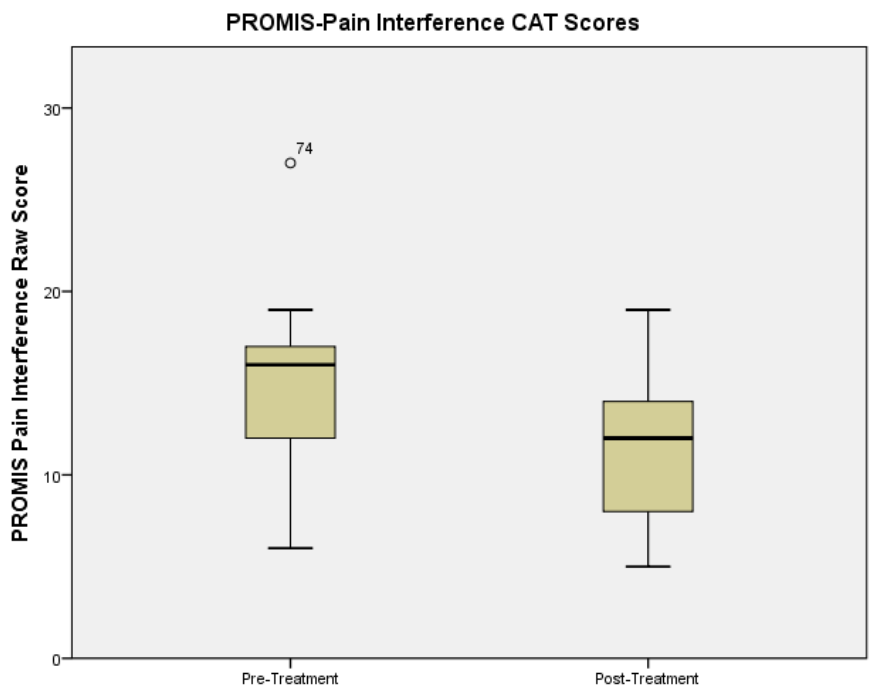

Figure 3. Pain interference scores

A significant group of patients did not pursue interdisciplinary treatment and no outcome data is available to compare with the patients who completed the program. However, the 45 patients who did reduce or eliminate opioids, their risk for overdose and diversion is probably significantly lower and their function is clearly improved, along with functional existence.

Perhaps patients who chose not to participate in interdisciplinary care have pain that was opioid responsive, and made the right decision. On the other hand, it is likely patients who did not participate would have benefitted if they had chosen to participate.

In any event, patients do need alternatives to continued chronic opioid therapy and interdisciplinary treatment is a viable option for at least some of the large number of patients who have been treated with opioids.

\subsection{Tapering off}

Many patients are prescribed opioid therapy by one doctor and then continue chronic opioid therapy with another doctor. Once patients have been exposed to opioids for a prolonged period of time, it becomes difficult to change the pain management approach and extinguish opioid-liking behaviors. However, continuing chronic opioid therapy that was initiated by another doctor is not addressed well in current guidelines. The single prescriber principle, interpreted literally, would mean that "taking over" opioid prescribing from another doctor 
would be prohibited. The reality is that patients change insurance, move, and choose to change doctors over the course of years for a number of valid reasons. Existing opioid therapy may not be an indication for continuing chronic opioid therapy, and primary care physicians, as well as specialists, need to be prepared to refer patients for detoxification if guidelines for opioid therapy cannot be met due to a lack of a proper pain diagnosis or red flags for abuse exist. Legitimate need is reassessed on a regular basis.

Patients may refuse detoxification as a means to continue opioid therapy. The prescribing physician should be reluctant to allow a patient to "go cold turkey" and should have some skill and understanding of tapering opioids. A gradual but firm reduction over a period of weeks is adequate for most patients. Patients with addiction should be referred for addictionology care and encouraged to receive expert help. Not all opioids can be tapered, such as Methadone, without a special attachment to the DEA certificates. Physicians trained in addictionology are best suited to treat patients who overlap pain and opioid dependence.

\section{Clinical vignette}

An elderly couple took different doses of hydrocodone from different doctors. They began sharing medication. Both needed to be tapered off and they refused and were discharged. Signed, written opioid agreements were in effect, which helped diffuse the situation.

Lesson learned-having opioid treatment agreements signed by the patient are helpful when patients need to be tapered of opioid and/or discharged for a medical practice. Patients who are terminated from a medical practice for cause should be sent a certified letter and followed for 30 days while alternative care is arranged.

Patients may be tapered off opioid over a period of days to weeks. Rapid Benzodiazepine withdrawal is associated with seizures and should proceed slowly in conjunction with psychiatric care if accessible. Clonidine patch $0.1 \mathrm{mg} /$ day may be helpful managing symptoms of opioid withdrawal, as well as hydroxyzine as an anxiolytic.

\section{REMS}

Risk evaluation and mitigation strategies (REMS) training is required for long acting and sustained release opioid prescribing. These measures are varied depending on the specific opioid preparation. Standardization of REMS requirements will eventually assist to meet guidelines [84].

\subsection{Alternatives to chronic opioids}

Tamper resistant preparations, buprenorphine, tramadol and new agents may help reduce the diversion associated with chronic opioid therapy. Interdisciplinary evaluations including interventional pain evaluations, psychological and physical therapy evaluations invariably 
lead to alternatives to chronic opioid therapy. Many chronic pain patients may be managed without opioids, and adjunctive medications enhance sleep, diminish depression and anxiety observed as comorbidities.

\subsection{Guidelines}

Multiple guidelines have been promulgated for opioid treatment of chronic pain. Experts in the field have published guidelines but new information about the risks of opioids necessitates new guidelines at this time. The American Society of Interventional Pain Physicians (ASIPP) updates controlled substance guidelines every two years. This exhaustive effort is available for download on the internet at www.asipp.org [85].

\subsection{Labeling}

In 2013, The Food and Drug Administration in the United States required new labeling information for opioids that are long acting:

\section{"TRADENAME is:}

- A strong prescription pain medicine that contains an opioid (narcotic) that is used to manage pain severe enough to require daily around-the-clock, long-term treatment with an opioid, when other pain treatments such as non-opioid pain medicines or immediate-release opioid medicines do not treat your pain well enough or you cannot tolerate them.

- A long-acting (extended-release) opioid pain medicine that can put you at risk for overdose and death. Even if you take your dose correctly as prescribed you are at risk for opioid addiction, abuse, and misuse that can lead to death.

- Not for use to treat pain that is not around-the-clock."

The use of long acting drugs for acute post-operative pain should be limited to special circumstances such as opioid tolerance or burn pain.

Recently, the Federation of State Medical Boards issued a new model policy including the following statement: "Additionally, providers should not continue opioid treatment unless the patient has received a benefit, including demonstrated functional improvement." [86] Most studies of opioids for chronic pain have shown incremental improvements in pain but have failed to show functional improvement. Therefore, it seems as though chronic opioid therapy is unlikely to continue as an accepted treatment for most patients.

Washington State has developed new workers' compensation guidelines in response to an epidemic of overdoses. [87] These guidelines are an attempt to objectify treatment for subjective symptoms. The guidelines restrict the use of chronic opioid therapy to very few special cases. The guidelines reserve opioids for VAS $>7$ and limit the dose to $120 \mathrm{mg} /$ day of oral morphine equivalents. The duration of treatment is limited to weeks. Continuation of opioids must be associated with a $30 \%$ improvement on a 2-question instrument for pain and function. Interestingly, the guidelines allow for marijuana use even though marijuana use has been 
associated with the use of more dangerous illicit substances. Restrictive guidelines such as these are fraught with contradiction and the potential for limiting access to therapy.

New opioid prescribing guidelines with a "safe harbor" prescribing clause including doses and duration of intervals between follow -up visits for reevaluation and prescription refills. Most prescribing laws, rules and guidelines mandate a single prescriber and pharmacist yet a single decision maker model is a major factor in making an individual physician vulnerable to disciplinary action.

\subsection{Clinical vignette}

An elderly obese woman with intractable severe pain was bedridden and demanded more opioid. Her bedridden status was confirmed and no additional opioid was prescribed. She responded by saying "you want me to be in pain".

Lesson learned-in the current environment, increases in opioid doses need to be associated with increased function.

\subsection{Cancer pain}

The use of opioids for cancer pain is excluded from restrictions in most guidelines. However, many patients with cancer survive long-term and are really chronic pain patients. Cancer treatment may produce chemotherapy related neuropathy, radiation plexopathy, and chronic post-operative pain such as post mastectomy syndrome, post thoracotomy syndrome and phantom pain syndrome. Pathologic fractures, especially vertebral body fractures, respond to interventional procedures. Interventional options for vertebral fractures include vertebroplasty, facet injections, and lysis of adhesions, quadratus lumborum or psoas injections, or transforaminal catheter techniques for chronic pain.

Neuromodulation may be useful in patients with neuropathic pain resulting from successful cancer treatment. Patients need to be evaluated for myofascial pain, radiculopathy and other common pain syndromes with careful history taking and physical examination. Terminally ill patients do have options for treatment other than escalating opioid doses. Trigger point injections, lysis of adhesions and other interventional therapies are often very helpful managing patients with cancer who may or may not ultimately die from neoplasia.

CLINICAL VIGNETTE patient with pain in the groin, scrotum and sacral area following radiation left the patient unable to sleep in any position other than in a chair in a knees-tochest position. The patient responded to sacral electrode stimulation bilaterally at S3. A year later, the patient had more pain and responded to stimulation at S2.

Lesson learned-Following aggressive cancer treatment, there are devastating pain conditions that are not terminal but do respond to interventional techniques but not to opioids.

Cancers of the cervix, rectum and other tissues produce pelvic pain syndromes that are often difficult to treat. Patients who have undergone abdominal-perineal resections have pain syndromes that may not respond well to opioids. This group of patients may have 
pain with sitting and tenderness to palpation over the ischial tuberosity (Racz's sign). Ricardo Plancarte describes the inferior hypogastric block may provide significant relief in some of these patients. [88]

A unilateral inferior hypogastric block is the preferred procedure for patients with unilateral pain and ischial tenderness. The inferior hypogastric plexus is more anatomically defined compared to the superior hypogastric plexus, which is more diffuse. A diagnostic block should be performed, preferably with a curved blunt needle, before a neurolytic block with phenol 6\%, 4-5 ml. [89] Erdine reported a transdiscal approach that may be the most effective technique. [90]

"Morphinemia" (a lack of morphine) should not be considered as the primary problem in every patient with cancer related pain. Opioids are prescribed for patients who respond to them, but additional options are explored in order to respond to a patient in need of pain relief, who does not respond adequately to increasing doses of opioids.

Methylnaltrexone for opioid related constipation in palliative care patients may be used when laxatives and other measures are inadequate. Constipation can cause abdominal pain and treating this with more opioid continues the cycle. The dose of methylnaltrexone is $0.15 \mathrm{mg} / \mathrm{kg}$.

Opioids also control rest pain, but not movement related pain. Opioids do reduce the likelihood of a patient becoming bedridden. Metastases usually do not invade vertebral pedicles early, and patients respond to lysis of adhesions enough to be able to walk. [91,92]

Clinical vignette-a patient with spinal metastasis responded for 3 months to lysis of adhesions. The patient became bedridden again and responded to a second procedure.

Lesson learned-some patients with terminal cancer may have improved quality of life with interventional techniques that otherwise would not be produced with opioids alone.

Patients with upper abdominal cancer pain may benefit from splanchnic radiofrequency ablation. Quality of life and pain control have been improved in studies using this technique. [93]

Patients with cancer related pain should be evaluated for interventional procedures that may improve their quality of life and suffering. Patients with terminal illness may become isolated from medical specialists and be treated by mid-level practitioners who are unfamiliar with options other than opioid escalation. Cancer pain treatment requires a team approach to afford optimal care.

Other conditions beyond cancer are legitimate palliative diagnosis for opioid use. Patients with end stage coronary artery disease and congestive heart failure are treated with morphine, not for chest pain, but for the venous dilatory effect, decrease cardiac preload, and reduction in shortness of breath. Patients who are bedridden with osteoporotic fractures are another example of patients with chronic pain at the end of life, and opioids are a compassionate treatment companion. Every drug used for pain has toxicity and side effects that sometimes precludes its use. Sometimes opioids are the least toxic option in the palliative care setting. 


\section{Conclusions}

Patients who request relatively small doses of opioids for conditions such as arthritis pain often do well over a period of years. This experience reinforces a practitioner's belief in the efficacy of chronic opioid therapy. However, addictionologists and pain specialists often witness a very different side of pain treated with opioids.

The prescribing clinician strives to improve the ability to identify patients who will do poorly with opioids, but we also strive to identify patients who will do well with this option. Generally, lower doses, less potent drugs, and shorter durations of therapy are associated with improved outcome and reduced adverse events. Some have suggested that opioids are to be used intermittently, not on a daily basis, for "breakthrough pain" only, along with other drug classes for "basal" analgesia. Others believe long-acting pharmacokinetically smooth agents are best suited for chronic pain.

The public health problem of overdose deaths has overridden the notion that the individual patient and their physician are free to use opioids for chronic pain without fear of legal and regulatory action and physicians need to anticipate the substantial shift in policy of regulators who authorize the privilege of practicing medicine.

Physicians are encouraged to err on the side of less opioid, rather than more opioid, and improve their skills in providing patient satisfaction with other drugs for chronic pain known as adjuncts. Non-drug treatments for pain need to be maximized as well prior to initiating opioid therapy. Tramadol and low dose potent opioids with defined frequent follow-up visits for refills are a necessary part of the practice of standard care despite the lack of long term randomized controlled trials.

Although contradictory to the patient/physician relationship, physicians must improve their ability to say "no" to the patient who demands opioids. This is weighed against alienating patients who have legitimate pain, but co-morbidities that place them at risk for bad outcomes from chronic opioid therapy. [94] Pain research, public education, patient education and medical education need to improve so that pain can be treated more successfully and safely. Improved diagnosis and treatment should lead to more cost effective treatment.

\section{Author details}

Hans Hansen ${ }^{1}$, Carl E. Noe² and Gabor B. Racz ${ }^{3}$

1 The Pain Relief Centers, Statesville, North Carolina, USA

2 University of Texas Southwestern Medical Center, Dallas, Texas, USA

3 Texas Tech University Health Science Center, Lubbock Texas, USA 


\section{References}

[1] http://healthyamericans.org/reports/drugabuse2013/, 2013

[2] Sullivan, M.D., Ballantyne, J.C.: What are we learning with long term opioid therapy?Archives of Internal Medicine (2012) 172:433-434

[3] Braden, J.B., Young, A., Sullivan M.D., et.al.: Predictors of change in pain and physical functioning among post-menopausal women with recurrent pain conditions in the women's health initiative observational cohort. The Journal of Pain (2012) 13:64-72

[4] Laxmaiah Manchikanti, MD, et al. American Society of Interventional Pain Physicians (ASIPP) Guidelines for Responsible Opioid Prescribing and Chronic Non-Cancer Pain: Part 1 - Evidence Assessment. Pain Physician 2012; 15: S67-S116

[5] Report of the International Narcotics Control Board for 2004. New York, United Nations, 2005. www.incb.org/pdf/e/ar/2004/incb_report_2004_full.pdf

[6] Edlund MJ, Martin BC, Devries A, Fan MY, Braden JB, Sullivan MD. Trends in use of opioids for chronic noncancer pain among individuals with mental health and substance use disorders: the TROUP Study. Clin J Pain 2010; 26:1-8.

[7] Sullivan MD, Edlund MJ, Fan MY, Devries A, Brennan Braden J, Martin BC. Risks for possible and probable opioid misuse among recipients of chronic opioid therapy in commercial and Medicaid insurance plans: the TROUP Study. Pain 2010; 150:332-339.

[8] Fleming MF, Balousek SL, Klessig CL, Mundt MP, Brown DD. Substance use disorders in a primary care sample receiving daily opioid therapy. J Pain 2007; 8:573-582.

[9] Warner M, Chen LH, Makuc DM, Anderson RN, Miniño AM. Drug poisoning deaths in the United States, 1980-2008. NCHS data brief, no. 81. National Center for Health Statistics, Hyattsville, MD, 2011.

[10] Centers for Disease Control and Prevention. Vital signs: Overdoses of prescription opioid pain relievers - United States, 1999-2008. MMWR. Morb Mortal Wkly Rep $2011 ; 60: 1487-1492$.

[11] Pain Med. 2013 Oct;14(10):1534-47. doi: 10.1111/pme.12183. Epub 2013 Jul 10. The economic burden of opioid-related poisoning in the United States. Inocencio TJ1, Carroll NV, Read EJ, Holdford DA.

[12] Pain Physician. 2012 Jul;15(3 Suppl):ES9-38. Opioid epidemic in the United States. Manchikanti L1, Helm S 2nd, Fellows B, Janata JW, Pampati V, Grider JS, Boswell MV.

[13] Pain Physician. 2012 Jul;15(3 Suppl):ES9-38. Opioid epidemic in the United States. Manchikanti L1, Helm S 2nd, Fellows B, Janata JW, Pampati V, Grider JS, Boswell MV. 
[14] Open Med. 2012 Apr 10;6(2):e41-7. Print 2012. Trends in prescriptions for oxycodone and other commonly used opioids in the United States, 2000-2010. Kenan K1, Mack K, Paulozzi L.

[15] Pain Physician. 2014 Mar-Apr;17(2):E119-28. Assessment of the trends in medical use and misuse of opioid analgesics from 2004 to 2011. Atluri S, Sudarshan G, Manchikanti L1.

[16] IMS Institute for Healthcare Informatics. The use of medicines in the United States: Review of 2011. April 2012. www.imshealth.com/ims/Global/Content/Insights/IMS \%20Institute\%20for\%20Healthcare\%20Informatics/IHII_Medi-

cines_in_U.S_Report_2011.pdf

[17] Pain. 2013 Dec;154 Suppl 1:S94-100. doi: 10.1016/j.pain.2013.09.009. Epub 2013 Sep 11. Opioid therapy for chronic pain in the United States: promises and perils. Sullivan MD1, Howe CQ.

[18] Clin Perinatol. 1991 Mar;18(1):1-22. Animal models of opiate, cocaine, and cannabis use. Hutchings DE1, Dow-Edwards D.

[19] Chou R, Huffman L. Use of Chronic Opioid Therapy in Chronic Non-cancer Pain: Evidence Review. American Pain Society, Glenview, IL, 2009. www.ampainsoc.org/ library/pdf/Opioid_Final_Evidence_Report.pdf

[20] Governale L. Outpatient prescription opioid utilization in the U.S., years 2000 - 2009. Drug Utilization Data Analysis Team Leader, Division of Epidemiology, Office of Surveillance and Epidemiology. Presentation for U.S. Food and Drug Administration, July 22, 2010. www.fda.gov/downloads/AdvisoryCommittees/CommitteesMeetingMaterials/Drugs/AnestheticAndLifeSupportDrugsAdvisoryCommittee/ UCM220950.pdf

[21] Woolfe, SH. The Power of Prevention and What It Requires. JAMA 2008: 299; 2437-2439

[22] Time Magazine. Friday, May 2, 2008. Kathleen Kingsbury.

[23] Krueger, A. Lancet May 2003

[24] Greene, Carmen. 2005

[25] Donavan, MI. J of Pain Symptom Manage. 1999: 18; 38-48

[26] The Arthritis Foundation, "Pain in America: Highlights from a Gallop Survey.", 2000

[27] Smith, BH, et al. The Impact of Chronic Pain in the Community. Fam Pract 2001: 18 (3): $292-9$

[28] Stewart, WF, et al. Loss Productive Time and Cost due to Common Pain Conditions in the U.S. Workforce. JAMA (2003) 290: 18, p. 2446

[29] Lawrence, RC, et al. Arthritis and Rheum. 1998: 41 (5): 778-799 
[30] Makela, M, et al. Prevalence, Determinence, and Consequences of Chronic Neck Pain in Finland. AMJ Epidemiol 134: 1356-1357, 1991

[31] Kohlberg, L., LaCrosse, J., \& Ricks, D. (1972). The predictability of adult mental health from childhood behavior. In B. Wolman (Ed.), Manual of child psychopathology (pp. 1217-1284). New York: McGraw-Hill.

[32] Merskey H, Bogduk N. Task Force on Taxonomy of the International Association for the Study of Pain. Classification of Chronic Pain: Descriptions of Chronic Pain Syndromes and Definition of Pain Terms. 2nd ed. IASP Press, Seattle, WA, 1994.

[33] Neuropsychopharmacology. 2014 Apr 1. doi: 10.1038/npp.2014.77. Persistent Pain Facilitates Response to Morphine Reward by Downregulation of Central Amygdala GABAergic Function. Zhang Z, Tao W, Hou YY, Wang W, Lu YG, Pan ZZ

[34] Institute of Medicine (IOM). Relieving Pain in America: A Blueprint for Transforming Prevention, Care, Education, and Research. The National Academies Press, Washington, DC, June 29, 2011.

[35] Pizzo PA, Clark NM. Alleviating suffering 101 - Pain relief in the United States. N Engl J Med 2012; 367:197-198.

[36] Martin BI, Turner JA, Mirza SK, Lee MJ, Comstock BA, Deyo RA. Trends in health care expenditures, utilization, and health status among US adults with spine problems, 1997-2006. Spine (Phila Pa 1976) 2009 34:2077-2084.

[37] Cicero TJ, Wong G, Tian Y, Lynskey M, Todorov A, Isenberg K. Co-morbidity and utilization of medical services by pain patients receiving opioid medications: Data from an insurance claims database. Pain 2009; 144:20-27.

[38] Sjøgren P, Grønbæk M, Peuckmann V, Ekholm O. A population-based cohort study on chronic pain: the role of opioids. Clin J Pain 2010; 26:763-769.

[39] Substance Abuse and Mental Health Services Administration. Results from the 2010 National Survey on Drug Use and Health: Summary of National Findings. NSDUH Series H-41, HHS Publication No. (SMA) 11-4658. Substance Abuse and Mental Health Services Administration, Rockville, MD, 2011. www.samhsa.gov/data/ NSDUH/2k10NSDUH/2k10Results.pdf.

[40] Diabetes and Cardiovascular Disease Executive Summary Conference Proceeding for Healthcare Professionals From a Special Writing Group of the American Heart Association. Scott M. Grundy, MD, PhD; Barbara Howard, PhD; Sidney Smith Jr, MD; Robert Eckel, MD; Rita Redberg, MD; Robert O. Bonow, MD. http://circ.ahajournals.org/content/105/18/2231.full

[41] Pain. 1986 May;25(2):171-86. Chronic use of opioid analgesics in non-malignant pain: report of 38 cases. Portenoy RK, Foley KM. 
[42] http://www.unodc.org/unodc/en/frontpage/the-1912-hague-international-opium-convention.html

[43] JAMA. 2011 Apr 6;305(13):1315-21. doi: 10.1001/jama.2011.370. Association between opioid prescribing patterns and opioid overdose-related deaths. Bohnert AS1, Valenstein M, Bair MJ, Ganoczy D, McCarthy JF, Ilgen MA, Blow FC.

[44] Manchikanti L, Whitfield E, Pallone F. Evolution of the National All Schedules Prescription Electronic Reporting Act (NASPER): A public law for balancing treatment of pain and drug abuse and diversion. Pain Physician 2005; 8:335-347.

[45] Centers for Disease Control and Prevention. CDC grand rounds: Prescription drug overdoses - a U.S. epidemic. MMWR Morb Mortal Wkly Rep 2012; 61:10-13.

[46] Centers for Disease Control and Prevention. Vital signs: Overdoses of prescription opioid pain relievers - United States, 1999-2008. MMWR. Morb Mortal Wkly Rep 2011; 60:1487-1492.

[47] Pain Physician. 2012 Jul;15(3 Suppl):ES9-38. Opioid epidemic in the United States. Manchikanti L1, Helm S 2nd, Fellows B, Janata JW, Pampati V, Grider JS, Boswell MV.

[48] Drug Alcohol Rev. 2014 Apr 16. doi: 10.1111/dar.12143. Opioid-related mortality and filled prescriptions for buprenorphine and methadone. Wikner BN1, Ohman I, Seldén T, Druid H, Brandt L, Kieler H.

[49] Pain Physician. 2003 Apr;6(2):173-8. Prevalence of illicit drug use in patients without controlled substance abuse in interventional pain management. Manchikanti L1, Pampati V, Damron KS, Beyer CD, Barnhill RC.

[50] Deyo RA, Smith DH, Johnson ES, Donovan M, Tillotson CJ, Yang X, Petrik AF, Dobscha SK. Opioids for back pain patients: Primary care prescribing patterns and use of services. J Am Board Fam Med 2011; 24:717-727.

[51] Manchikanti L, Abdi S, Atluri S, Balog CC, Benyamin RM, Boswell MV, Brown KR, Bruel BM, Bryce DA, Burks PA, Burton AW, Calodney AK, Caraway DL, Cash KA, Christo PJ, Colson J, Damron KS, Datta S, Deer TR, Diwan S, Eriator I, Falco FJE, Fellows B, Geffert S, Gharibo CG, Glaser SE, Grider JS, Hameed H, Hameed M, Hansen HC, Harned M, Hayek SM, Helm II S, Hirsch JA, Janata JW, Kaye AM, Kaye AD, Koyyalagunta D, Lee M, Manchikanti KN, McManus CD, Pampati V, Parr AT, Pasupuleti R, Patel V, Pope JE, Sehgal N, Silverman SM, Singh V, Smith HS, Solanki DR, Tracy DH, Vallejo R, Wargo BW. American Society of Interventional Pain Physicians (ASIPP) guidelines for responsible opioid prescribing in chronic non-cancer pain: Part 1 - Evidence assessment. Pain Physician 2012; 15:S1-S66

[52] Am J Ind Med. 2013 Dec;56(12):1452-62. doi: 10.1002/ajim.22266. Epub 2013 Oct 10. Opioid poisonings and opioid adverse effects in workers in Washington State. Ful- 
ton-Kehoe D1, Garg RK, Turner JA, Bauer AM, Sullivan MD, Wickizer TM, Franklin GM.

[53] Richarz, U., Waechter, S., Sabatowski, R., Szczepanski, L., Binsfeld, H.: Sustained safety and efficacy of once -daily hydromorphone extended release compared to twice -daily oxycodone controlled release over 52 weeks in patients with moderate to severe chronic noncancer pain. Pain Practice 2013, 13:30-40.

[54] Afilalo, M., Etropolski, M.S., Kuperwasser, B., et.al: Efficacy and Safety of Tapentadol Extended Release Compared with Oxycodone Controlled Release for the Management of Moderate to Severe Chronic Pain Related to Osteoarthritis of the Knee. Clinical Drug Investigation 2010; 30:489-505.

[55] Lerner, D., Chang, H., Rogers, W.H., et.al.: Imputing at-work productivity loss using results of a randomized controlled trial comparing tapentadol extended release and oxycodone controlled release for osteoarthritis pain. Journal of Occupational and Environmental Medicine 54:933-938

[56] Steiner, D., Munera, C., Hale, M., Ripa, S., Landau, C.: Efficacy and safety of buprenorphine transdermal system for moderate to severe low back pain: a randomized, double blind study. Journal of Pain 12:1163-173

[57] Bohnert A.S., Valenstein, M., Bair, M.J., et.al.: Association between opioid prescribing patterns and opioid overdose -related deaths. JAMA (2011) 305:1315-1321.

[58] Miller, M., Sturmer, T., Azrael, D., Levin, R., Solomon, D.H.: Opioid analgesics and the risk of fractures in older adults with arthritis Journal of the American Geriatric Society (2011) 59:430-438

[59] Saunders, K.W., Dunn, K.M., Merrill, J.O., et.al.: Relationship of opioid use and dosage levels to fractures in older chronic pain patients Journal of General Internal Medicine 25(4):310-315

[60] Gomes, T., Redelmeier D.A., Juurlink D.N., et.al;:: opioid dose and risk of road trauma in Canada: a population-based study JAMA (2010) 173:196-201

[61] Seal, K.H., Shi, Y., Cohen, G., et.al.: Association of mental health disorders with prescription opioids and high -risk opioid use in US veterans of Iraq and Afghanistan JAMA (2012) 307:940-947

[62] Lee M, Silverman SM, Hansen H, Patel VB, Manchikanti L. A comprehensive review of opioid-induced hyperalgesia. Pain Physician 2011; 14:145-161.

[63] Braden J.B., Edlund, M.J., Martin, B,C., et.al.: Trends in use of opioids by noncancer pain type 2000-2005 among Arkansas Medicaid and healthcare enrollees: results from the TROUP study Journal of Pain (2008) 9:1026-1035 
[64] Brede, E., Mayer, T.G., Gatchel, R.J.: Prediction of failure to retain work 1 year after interdisciplinary functional restoration in occupational injuries Archives of Physical Medicine and Rehabilitation (2012) 93:268-274

[65] Franklin G.M., Stover, B.D., Turner, J.A.,et.al: early opioid prescription and subsequent disability among workers with back injuries Spine (2008) 33:199-204

[66] Naliboff, B.D., Wu, S.M., Schieffer, B., et.al.: A randomized trial of 2 prescription strategies for opioid treatment of chronic nonmalignant pain Journal of Pain $12: 288-296$

[67] Peavy K.M., Banta-Green, C.J., Kingston, S., et.al.: "Hooked on " prescription-type opiates prior to using heroin: results from a survey of syringe exchange clients Journal of Psychoactive Drugs (2012) 44:259-265

[68] Manchikanti L, Whitfield E, Pallone F. Evolution of the National All Schedules Prescription Electronic Reporting Act (NASPER): A public law for balancing treatment of pain and drug abuse and diversion. Pain Physician 2005; 8:335-347.

[69] Wang J, Christo PJ. The influence of prescription monitoring programs on chronic pain management. Pain Physician 2009; 12:507-515

[70] Reifler LM, Droz D, Bailey JE, Schnoll SH, Fant R, Dart RC, Bucher Bartelson B. Do prescription monitoring programs impact state trends in opioid abuse/misuse? Pain Med 2012; 13:434-442.

[71] Yokell MA, Green TC, Rich JD. Prescription drug monitoring programs. JAMA 2012; 307:912; author reply 912-913.

[72] Paulozzi LJ, Kilbourne EM, Desai HA. Prescription drug monitoring programs and death rates from drug overdose. Pain Med 2011; 12:747-754.

[73] Gourlay DL, Heit HA, Almahrezi A. Universal precautions in pain medicine: A rational approach to the treatment of chronic pain. Pain Med 2005; 6:107-112.

[74] Lee M, Silverman SM, Hansen H, Patel VB, Manchikanti L. A comprehensive review of opioid-induced hyperalgesia. Pain Physician 2011; 14:145-161.

[75] Manchikanti L, Singh V, Caraway DL, Benyamin RM. Breakthrough pain in chronic non-cancer pain: Fact, fiction, or abuse. Pain Physician 2011; 14:E103-E117.

[76] https://archive.org/details/63310410R.nlm.nih.gov

[77] Soc Sci Med. 1984;18(6):515-23. Pain and the ethics of pain management. Edwards RB.

[78] http://www.cdc.gov/primarycare/materials/opoidabuse/docs/pda-phperspective-508.pdf

[79] Substance Abuse and Mental Health Services Administration. Results from the 2010 National Survey on Drug Use and Health: Summary of National Findings. NSDUH 
Series H-41, HHS Publication No. (SMA) 11-4658. Substance Abuse and Mental Health Services Administration, Rockville, MD, 2011. www.samhsa.gov/data/ NSDUH/2k10NSDUH/2k10Results.pdf.

[80] Substance Abuse and Mental Health Services Administration. Results from the 2010 National Survey on Drug Use and Health: Mental Health Findings. NSDUH Series H-42, HHS Publication No. (SMA) 11-4667. Rockville, MD: Substance Abuse and Mental Health Services Administration, 2012. www.samhsa.gov/data/NSDUH/ 2k10MH_Findings/2k10MHResults.pdf

[81] Smith, T.J., Coyne, P.J., Staats, P.S., et.al.: An implantable drug delivery system for refractory cancer pain provides sustained pain control, less drug-related toxicity, and possibly better survival compared with comprehensive medical management. Annals of Oncology 16:825-833, 2005

[82] Tao, W., Nguyen, A.P., Ogunnaike, B.O., Craig, M.G.: Use of a 23 gauge continuous spinal catheter for labor analgesia: a case series International Journal of Obstetrical Anesthesia 20(4):351-4

[83] Dominguez E, Sahinler B, Bassam D, Day M, Lou L, Racz GB, Raj PP: Predictive Value of intrathecal Narcotic Trials for Long-Term therapy with Implantable Drug Administration systems in Chronic Non-Cancer Pain Patients. Pain Practice 2(4)315-325, 2002

[84] Thompson CA. Long-awaited opioid REMS affects prescribers more than dispensers. Am J Health Syst Pharm 2011; 68:963-967.

[85] Manchikanti L, Abdi S, Atluri S, Balog CC, Benyamin RM, Boswell MV, Brown KR, Bruel BM, Bryce DA, Purks PA, Burton AW, Caraway DL, Christo PJ, Colson J, Damron KS, S, Deer TR, Diwan S, Eriator I, Falco FJE, Fellows B, Geffert S, Gharibo CG, Glaser SE, Grider JS, Hameed H, Hameed M, Hansen H, Harned M, Hayek SM, Helm II S, Hirsch JA, Janata JW, Jorden AE, Kaye AM, Kaye AD, Koyyalagunta D, Lee M, Manchikanti KN, McManus CD, Pampati V, Parr AT, Pasupuleti R, Patel V, Pope JE, Ruan X, Sehgal N, Silverman SM, Singh V, Smith HS, Solanki DR, Tracy DH, Vallejo R, Wargo BW, Trescot AM. American Society of Interventional Pain Physicians (ASIPP) guidelines for responsible opioid prescribing in chronic non-cancer pain: Part 2 - Guidance. Pain Physician 2012; 15:S67-S116.

[86] Federation of State Medical Boards Model Policy on the Use of Opioid Analgesics in the Treatment of Chronic Pain July 2013

[87] Franklin G.M., Mal, J., Turner, J., et.al.: Bending the prescription opioids dosing and mortality curves: impact of the Washington State opioid dosing guidelines American Journal of Industrial Medicine (2012) 55: 325-331

[88] Racz GB, O Arter, C Noe, JE Heavner: Diagnostic and neurolytic hypogastric plexus blockade for pelvic pain. Abs NYPGA, 293: 1989. 
[89] Racz GB, Noe C Colvin J, Heavner JE: Sympathetic nerve block, pelvic, hypogastric plexus block. In Raj JJ (ed.): Practical Management of Pain, Second Edition., 813-817, 1992.

[90] Erdine, S., Yucel, A.: Transdiscal approach for hypogastric plexus block Regional anesthesia and pain medicine 28:304-308

[91] Arter OE, Racz GB: Pain Management of the Oncologic Patient. Seminars in Surgical Oncology 6:162-172, 1990

[92] Racz, G.B., Day, M.R., Heavner,J.E., Smith, J.P.: The Racz Procedure: Lysis of epidural adhesions (Percutaneous Neuroplasty) In: Comprehensive treatment of chronic pain by medical interventional and integrative approaches. American Academy of Pain Medicine Ed. T.R. Deer, et. al. p 521-534 Springer publisher

[93] Papadopoulos, D., Kostopanagiotou, G., Batistaki, C.: Bilateral Thoracic Splanchnic Nerve Radiofrequency Thermocoagulation for the Management of End-Stage Pancreatic Abdominal Cancer Pain Pain Physician 2013; 16:125-133

[94] Wang, E., Golden, A., Butterworth, P.J.: How to say no The Permanente Journal 6(4) http://xnet.kp.org/permanentejournal/fall02/sayno.html 